\title{
Induction core alloys for heavy-ion inertial fusion-energy accelerators
}

\author{
Arthur W. Molvik* and Andris Faltens ${ }^{\dagger}$ \\ Heavy-Ion Fusion Virtual National Laboratory, Ernest Orlando Lawrence Berkeley National Laboratory, \\ Berkeley, California 94720-8201
}

(Received 14 March 2002; published 5 August 2002)

\begin{abstract}
Induction core alloys are evaluated that are appropriate for heavy-ion induction accelerators to drive heavy-ion inertial fusion (HIF) power plants. Parameters evaluated include the usable flux swing and the energy loss over a range of magnetization rates of $\sim 10^{5}-10^{7} \mathrm{~T} / \mathrm{s}$, corresponding to pulse durations of $\sim 20$ to $0.2 \mu \mathrm{s}$, respectively. The usable flux swing, for minimum core losses, extends from near the reversed remanent field to about $80 \%$ of the saturation field. The usable flux swing is enhanced, with little increase in losses, by annealing the core after winding. Maintaining low energy loss at high magnetization rates requires insulation to block interlaminar eddy currents. To obtain annealed cores with a high ratio of remanent to saturation magnetic field, the insulation must withstand annealing temperatures and apply minimum mechanical stress to the core during cooldown. We find that commercially available insulating coatings for amorphous metals either break down near $10^{6} \mathrm{~T} / \mathrm{s}$ (a factor of 10 below the requirement), or do not achieve the maximum remanent field and hence the usable flux swing after annealing. More satisfactory coatings are available for silicon steel and nanocrystalline alloys, which could have applications in HIF. Amorphous alloys are capable of meeting most HIF needs, especially with improved coatings.
\end{abstract}

DOI: 10.1103/PhysRevSTAB.5.080401

\section{INTRODUCTION}

An induction linac accelerator (driver) to drive a heavy-ion fusion (HIF) power plant needs a few $\times 10^{7} \mathrm{~kg}$ of magnetic material in induction cores to accelerate heavy ions to an energy in the $\mathrm{GeV}$ range and deliver several megajoules per pulse to a target [1]. With this much mass, induction cores and the associated pulsers form one of the major cost areas for HIF [2]. To achieve a cost goal of $<\$ 10^{9}$ for a driver, induction core costs must be much less than the present $\sim \$ 20-\$ 150 / \mathrm{kg}$ in small quantities. A near term integrated-beam experiment, currently being evaluated, could use the order of $30-150 \times 10^{3} \mathrm{~kg}$ (depending on the beam duration between 0.25 and $1 \mu$ s flattop and the final energy of 10-20 MeV). Here performance/cost ratio enhancements are also helpful.

This paper will concentrate on performance optimization. The most important performance parameters are high flux swing to reduce the required mass of induction cores and low loss to reduce the cost of pulsers and to increase the accelerator efficiency. We will discuss examples of the effect of alloy choice on the mass and power losses of a power-plant sized accelerator. Other important performance parameters are reproducibility in a single core, so that every beam pulse receives identical acceleration and manipulation with high precision, and a small spread in

\footnotetext{
*Email address: molvik1@1lnl.gov

Present address: Lawrence Livermore National Laboratory, Livermore, CA 94550.

†Present address: Ernest Orlando Lawrence Berkeley National Laboratory, 1 Cyclotron Road, Berkeley, CA 94720.
}

PACS numbers: 75.50.Bb, 75.50.Kj, 75.60.-d, 52.58.Hm

performance between similar cores, to minimize the need to carefully measure and match cores to pulsers or to adjust each pulser to optimize it for a particular core, to provide similar acceleration in each gap, and for ease of replacing with a spare. However, one needs to keep in mind that to minimize the total mass of induction cores, there is much more gained by induction accelerator innovations that reduce the acceleration pulse duration or the diameter of the accelerator encircled by cores than by maximizing the flux swing of the cores.

Heavy-ion inertial fusion has attractive prospects for generating electrical power at reasonable cost, with high availability, safety, and low activation $[1,3,4]$. Advantages with HIF accrue from the separability of the driver and the target factory from the chamber and the protection of chamber walls from radiation by thick liquid walls. The modularity or separability of the driver, the chamber, and the target factory enables more independent development of each component. This reduces the cost of development and facilitates upgrading. Furthermore, within the driver, components such as quadrupole magnets and induction cells are replicated thousands of times, leading to low development costs and easier maintenance. The thick liquid walls are composed of flibe, a low-activation molten salt containing fluorine, lithium, and beryllium $[3,4]$. They are typically formed from static or oscillating jets [5] of flibe, which shield the solid walls of the vacuum chamber from neutrons and gamma rays and also generate tritium from neutron interactions with the lithium in a continuously replaced blanket. This eliminates the need to shut down the power plant for blanket replacement and thereby provides the possibility of high availability. The low activation enables recycling and reduces activated waste to be disposed 
of, resulting in an environmentally attractive power-plant concept.

HIF research facilities are just beginning to study powerplant-scale beams (a single beam out of the order of a hundred beams expected in a power plant) at energies near an $\mathrm{MeV}$ [6]. One can expect that with much research and development required before we build a heavy-ion inertial fusion-energy power plant, and particularly because we are encouraging innovation, the first demonstration power plant will have evolved significantly from our present concept as presented here and in the references. Because the final goal cannot be narrowly defined, we have chosen to cover a wide parameter range (e.g., a factor of 100 in magnetization rate) in order to include most of the range likely to be relevant for an HIF power plant. We also attempt to discuss both selected and rejected techniques in sufficient detail to aid in later reconsiderations.

Our work concentrated on evaluating cores wound from iron-based amorphous metals, nanocrystalline alloys, and silicon steel. Previous accelerators have used other materials: nickel iron that we rejected as too expensive, pure iron that has much higher losses, and ferrite that has low flux swings, small diameters, and is best suited to pulse durations of the order of $50 \mathrm{~ns}$. Nanocrystalline materials satisfy all the technical requirements, except cost and perhaps lifetime, and could result in acceleration of $1 \mu \mathrm{s}$ or shorter pulses with the very high efficiency of $\geq 75 \%$ [7]. Silicon steel could be satisfactory for the longer pulse durations. Amorphous materials should be less expensive, but the coating and annealing processes need further development, as will be discussed. As will be seen, we evaluated a small number of samples of each type of core, which might not be indicative of general performance. ${ }^{1}$

This paper is organized as follows: In Sec. II we discuss the principles and advantages of induction accelerators and methods of optimizing induction core performance. In Sec. III our experimental methods for measuring induction core properties and analyzing the results are discussed. In Sec. IV, we discuss the various alloys evaluated, first a general discussion and summary in Sec. IV A, then a discussion of amorphous, nanocrystalline, and silicon steel alloys in greater detail in Secs. IV B-D, respectively. In Sec. V, we discuss the requirements on, and the performance of, various coatings and identify improvements needed. Finally in Sec. VI, we summarize our conclusions.

\section{INDUCTION ACCELERATORS}

Induction accelerators have been selected by the U.S. HIF program because their high current and high

\footnotetext{
${ }^{1}$ This paper represents the authors' views and does not constitute an endorsement of any product or service by either the United States Government or the Regents of the University of California.
}

power capability eliminate the need for one or more storage rings to accumulate and then rapidly extract the ion beams [1]. Acceleration occurs from pulsing a voltage across the primary winding of a magnetic core, which then couples through an insulating vacuum barrier to induce an axial voltage along the multiple beams. This is shown schematically in Fig. 1, along with one candidate pulser architecture and the arrays of superconducting quadrupole magnets that transport the beams. The cores are reset to the negative remanent field, $-B_{r}$, slowly and with low losses between pulses. The full $B-H$ loop is thus asymmetric and quite different from the dc hysteresis loop. By timing the pulsers to reach full amplitude as the beam arrives, the ion beam experiences a succession of dc-like accelerating fields. In a power plant, the accelerator will be pulsed approximately 5 times per second.

In addition to square waves for acceleration, induction accelerators require ramped waveforms. These confine the head and tail of the beams against longitudinal expansion driven by space charge. These also adjust the beam velocity tilt towards the tail to control the length of the beam over much of the accelerator, especially at low energies. Shorter-length, higher current beams enable more efficient acceleration and a lower total mass of induction cores; however the maximum beam current that can be transported in magnetic quadrupoles increases with beam energy, and therefore these higher current beams could not be transported at low energy. Near the end of the accelerator, ramped acceleration pulses again place a carefully shaped velocity tilt on the few-hundred-nanosecond beam pulse. This compresses the beam to a shaped pulse of about $10 \mathrm{~ns}$ duration (as required by the target), over a drift-compression section a few hundred meters long. In addition, a possible architecture uses relatively crude main pulsers that approximate the desired waveforms, supplemented with occasional correction pulsers (possibly feedback controlled) that reduce the net waveform errors to an acceptable level, $<1 \%$ [8]. Correction pulsers are significantly more expensive, which increases the importance of minimizing the losses in the associated cores; thus a combination of inexpensive and premium cores might be required.

The coupling of the cores to the beams is determined by Faraday's law, which for our purposes is conveniently expressed as

$$
V \Delta t=A_{c} \Delta B
$$

where $V$ is the voltage induced across an insulated gap for a time $\Delta t(\mathrm{~s})$, by a core with a cross-sectional area $A_{c}\left(\mathrm{~m}^{2}\right)$ expressed as the equivalent solid metal area that is smaller than the geometrical area by the packing factor (PF), and a magnetic flux swing $\Delta B(T)$. The packing fraction should approach unity, otherwise the core outer diameter must increase to provide a sufficient cross-sectional area for the required volt seconds; adding material at the outer diameter increases the mass and cost of the cores. 


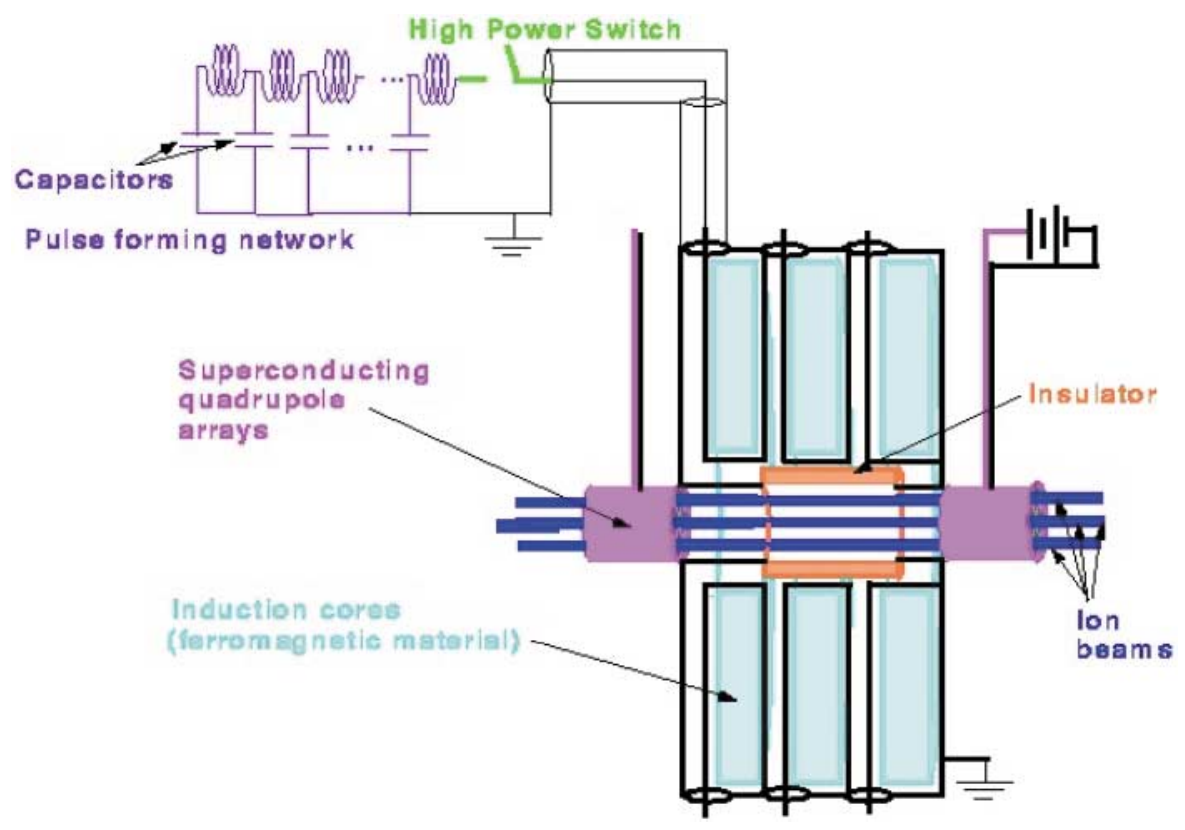

FIG. 1. (Color) Major components of an induction linac.

The relationship of the flux swing $\Delta B$ to $H$ and the drive current $I$ is complicated, being nonlinear, multivalued, and time dependent for the pulse durations of interest, Fig. 2. The desired accelerating voltage pulse is usually the given quantity, to be matched to an accuracy of a percent or so,

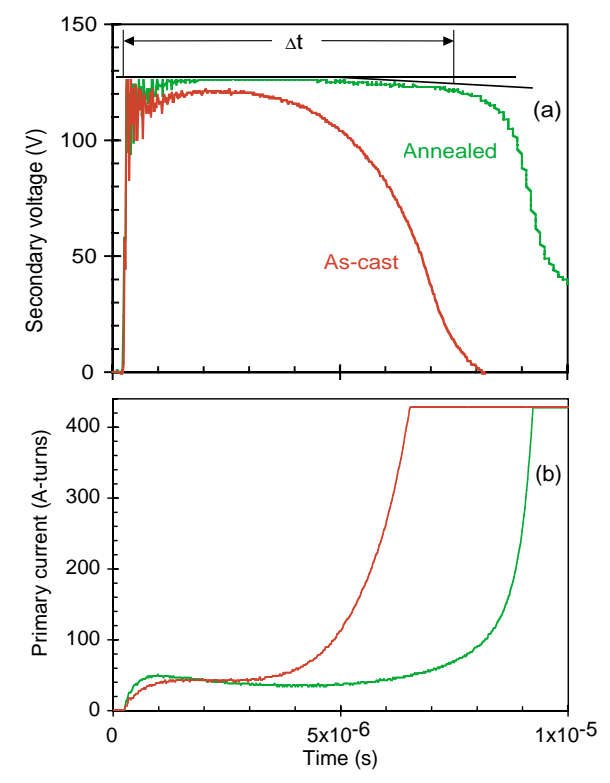

FIG. 2. (Color) Comparison of the (a) secondary voltage and (b) primary drive current before and after annealing of a METGLAS 2605 SC amorphous metal core that has mica paper interlaminar insulation. The usable flux swing, as indicated in (a) by $\Delta t$ and discussed in the text, increases significantly. and the drive current is the measured quantity. The goal is to reduce the magnitude and the time variations of this drive current. The integral of the $I-V$ product over time gives the energy to drive the core, which with the beam load, determines the accelerator efficiency. Because of the impracticality of recovering the energy left in a core at the end of a pulse, this energy is included in our losses. The core losses may be thought of as due to hysteresis and eddy currents, both of which are affected by the choice of tape thickness, insulation, and heat treatment.

The performance of amorphous alloys has been previously found to be significantly enhanced by magnetic annealing (also called field annealing or box annealing) where the alloy tape is heated to the range of $325-400{ }^{\circ} \mathrm{C}$ in an inert atmosphere while a magnetic field of $\sim 80$ A turns $/ \mathrm{m}$ is applied parallel to the tape by an axial current $[9,10]$. An example from our work is shown in Fig. 2. After magnetic annealing, the voltage waveform is more square; it is nearly flat for a longer duration. The pulser current to drive the core losses actually decreases in time and remains low for a longer duration before rising rapidly as the core approaches full saturation. Similar data from an annealed nanocrystalline core, Fig. 3 demonstrates a different behavior with a drive current that starts at a much lower value, even though the pulse duration is shorter and the magnetization rate is much higher (as shown by the higher voltage in Fig. 3), which, on a given alloy, would require a higher drive current. The drive current in Fig. 3 then increases steadily until near saturation, rather than decreasing in time after an initial peak as in Fig. 2. Unannealed amorphous metal cores have shown a standard deviation in loss per unit volume of 14\%-29\% [11]. The measurements of annealed cores, presented in this paper, show significantly smaller 

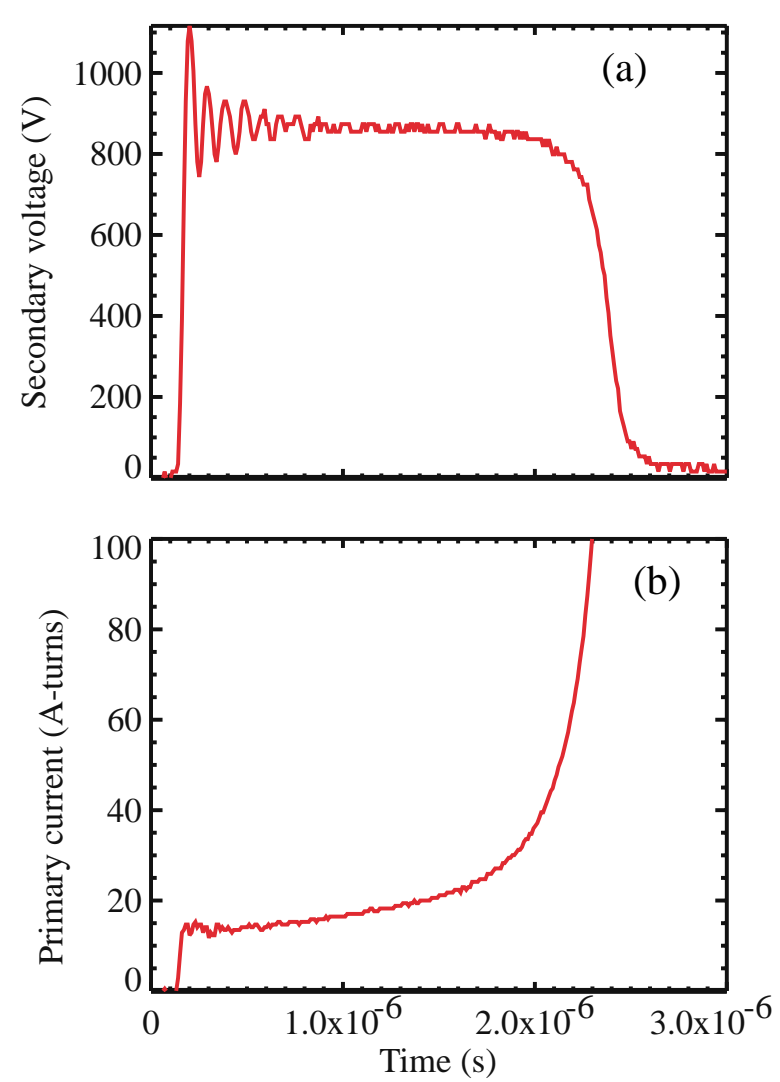

FIG. 3. (Color) Comparison of the (a) secondary voltage and (b) primary drive current for a FINEMET core, 982-3.

variations in loss, but with only a few samples of each. An alternative to annealing after winding is to anneal prior to winding into a core $[9,12]$. This will be discussed further in Sec. IV B.

Short pulse performance is strongly degraded by interlaminar eddy currents, unless interlaminar insulation is provided. We apply Faraday's law, Eq. (1), to a single lamination, $15-25 \mu \mathrm{m}$ thick and $0.01-0.2 \mathrm{~m}$ wide with a typical flux swing of $\Delta B=2.5 \mathrm{~T}$, for durations between $\sim 0.2$ and $20 \mu \mathrm{s}$. We find the average interlaminar voltage ranges from much less than 1 to $\sim 60 \mathrm{~V}$. The peak voltage can increase further by factors of 2-3 in cores with a relatively large radial buildup, as will be discussed in Sec. V. We also want to keep the cores from completely saturating to avoid very high voltages across the outer laminations. In addition to holding the interlaminar voltage without breakdown, the insulation must also withstand the temperatures encountered during the magnetic annealing described above and must not apply significant mechanical stress to the magnetic alloy during cooldown, or the core performance will be degraded. The requirements on insulation are discussed further in Sec. V.

The limit on how short a pulse is usable is determined by two main factors: interlaminar breakdown and the rise and fall times of the pulse relative to the duration of the usable portion. It is also more difficult to obtain high precision waveforms with shorter duration pulses.
Breakdown can be reduced by increasing the voltage holding of the insulation, subject to limitations discussed in Sec. V. Alternatively, breakdown can be reduced by reducing the width of the core sections (longitudinal extent in a linac), if the consequent reduction in axial packing fraction is acceptable.

The rise and fall times of the pulse must be accommodated within the flux swing of the core, so the core area must increase if the duration of these approaches the duration of the usable portion of the pulse. The rise and fall times are determined by the design of the pulser, the transmission line, and the geometry of the induction cell. Also, the useful portion of a pulse must match an ideal shape within a tolerance of $<1 \%$ [8]. Achieving this accuracy will usually require that the rise and fall times be shorter than the useful portion of the pulse. The purpose of this high-precision pulse shape is to maintain the longitudinal emittance below the level where chromatic aberrations would prevent focusing to the small spot size required by the fusion target.

When the beam energy is sufficiently high, the peak current, or shortness of the pulse, is no longer limited by beam transport. Then the optimum pulse duration is a compromise between increasing the costs of the pulser, transmission line, and induction cell geometry with shorter pulses versus increasing the area and costs of the induction cores with longer pulses. The optimization also needs to include the cost savings of a shorter accelerator with fewer quadrupole magnets that results from shorter, highervoltage pulses. Acceleration efficiency is not an issue: as shown on p. 450 of Ref. [7], the energy gain of the beam scales as $(d B / d t)^{2}$. The core losses shown in this paper all scale more slowly than $(d B / d t)^{1}$, as long as interlaminar breakdown does not occur, so the acceleration efficiency will increase as the pulse duration becomes shorter. Operation beyond $10^{7} \mathrm{~T} / \mathrm{s}$, by a factor of a few, could prove optimum.

Magnetic materials have been previously surveyed, with cores of $0.03 \mathrm{~kg}$ [12-14] to $0.6 \mathrm{~kg}$ [9], sometimes with interlaminar insulation that can withstand annealing $[9,10]$. Our earliest work used mica paper insulation, cowound with METGLAS 2605 SC [15,16]. Mica paper was chosen because it could withstand annealing temperatures allowing cores to be annealed after winding and not stress the cores during cooldown [10]. This enabled the change in performance after annealing to be evaluated for individual cores. Subsequently we located several core manufacturers who use inorganic insulating coatings and anneal the cores after winding. Cores from these sources were used for further tests described here [17-19]. We have previously published a survey of some of these materials [11].

As have previous studies of magnetic materials, we concentrated on investigating amorphous alloys of steel that can be formed into tapes of 15-25 $\mu \mathrm{m}$ thickness, at a much lower cost than by rolling steel and that offer flux swings near $2.5 \mathrm{~T}$ [10]. We also studied two additional 
classes of materials that show potential for heavy-ion induction accelerators. Three percent silicon steel, a standard material for transformers, offers flux swings exceeding $3 \mathrm{~T}$, at the expense of higher losses than amorphous alloys, and is available in tapes as thin as 25 and $50 \mu \mathrm{m}$ [9]. The higher flux swing results in a lower mass of induction cores that may compensate for an increase in losses, especially in the longer pulse length portions of an induction accelerator. Early conceptual designs of drivers used wide $50 \mu \mathrm{m}$ silicon steel in the long pulse portions [20]. At the other performance extreme are the nanocrystalline materials that offer losses a factor of 2 or more below those of amorphous materials, but at the expense of flux swings that are lower, near $2 \mathrm{~T}$, and costs that are currently higher [21]. These are most attractive for applications that require low losses. We have eliminated alloys, from our survey, that use significant amounts of expensive elements; e.g., alloys that use $9 \%$ or more of cobalt (currently $\sim \$ 15 / \mathrm{kg}$, sometimes higher [22]. We did not eliminate nanocrystalline materials that use $3 \%$ of niobium. Costs of niobium are estimated to be in the $\$ 30-\$ 50 / \mathrm{kg}$ range [23], so the cost of materials in a nanocrystalline alloy is $\sim \$ 1 / \mathrm{kg}$ more than for amorphous, noncobalt alloys. The standard amorphous alloys consist of about $80 \%$ iron, with smaller amounts of boron and silicon.

\section{EXPERIMENTAL METHODS}

To measure the properties of the cores, we discharge a $0.8 \mu \mathrm{F}$ capacitor bank through a thyratron switch into 1 to 40 primary turns wrapped around the minor cross section of the toroidal cores. The inductance of the pulser is $2.7 \mu \mathrm{H}$, determined from shorting the primary winding terminals. A reset current pulse, in the reverse direction, precedes the main pulse. For this work, we allow $15 \mathrm{~ms}$ for the reset current to decay to zero before the main pulse, leaving the core at the reversed remanent field, $-B_{r}$. In addition, we generally use a "ringback" circuit consisting of a diode string across the thyratron that resets the core to $-B_{r}$ immediately after the pulse. The usable flux swing is then the sum of $B_{r}$ plus $\sim 80 \%$ of the saturation magnetic field $B_{s}$, as we will show in Sec. IV A. We did not vary the $R C$ snubber network across the thyratron, during a sequence of pulses at different voltages and number of primary turns; consequently the pulser would ring after turn-on over certain ranges of magnetization rates, e.g., Fig. 3.

The current $I$, through the primary, is measured with a current transformer. The voltage, $V$, across a 1-turn secondary is measured with a $\times 1000$ high-voltage probe. The data are collected at the highest rate of a $100 \mathrm{MS} / \mathrm{s}$ digital oscilloscope that can fit the main pulse into 1000 samples, then are archived in spread-sheet format and analyzed off-line. The oscilloscope calibration was checked by the manufacturer to be within specifications (errors $<1 \%$ of full scale), the voltage probe attenuation was adjusted to be within $1 \%$ over the range of time bases used (10-100 ns time steps), and the current transformer/ terminator was also checked to be within $1 \%$. The current is recorded at two different gains, separated by no more than a factor of 25 , to increase the dynamic range of the 8-bit recorders from 256 to about 6000 . The higher gain is set to maintain the magnitude of the initial current, during the usable portion of the flux swing, at $20 \%-50 \%$ of full scale. The gain and baseline vertical position were adjusted to keep ringing on scale. Then, numerical integration could accurately obtain the flux swing and core losses, because the data rate was high enough to resolve multiple points on each cycle of a ringing waveform.

The mechanical parameters, for one of each type of core studied, are listed in Table I. These parameters include the

TABLE I. Mechanical specifications of each type of core tested. PF is the packing fraction.

\begin{tabular}{lccccccrc}
\hline \hline Alloy & Type & $\begin{array}{c}\text { Inner } \\
\text { diameter } \\
(\mathrm{m})\end{array}$ & $\begin{array}{c}\text { Outer } \\
\text { diameter } \\
(\mathrm{m})\end{array}$ & $\begin{array}{c}\text { Width } \\
(\mathrm{m})\end{array}$ & $\begin{array}{c}\text { Mass } \\
(\mathrm{kg})\end{array}$ & $\begin{array}{c}\text { PF } \\
\text { Volume } \\
\left(10^{-4} \mathrm{~m}^{3}\right)\end{array}$ & $\begin{array}{c}\text { Area } \\
\left(10^{-4} \mathrm{~m}^{2}\right)\end{array}$ \\
\hline 2605 SC & Mica-14 & 0.126 & 0.199 & 0.051 & 1.45 & 0.21 & 2.0 & 3.9 \\
2605 SC & MRTI-SC-2 & 0.131 & 0.185 & 0.022 & 1.70 & 0.78 & 2.3 & 4.7 \\
SA1 & NAM-MgMethylate & 0.127 & 0.251 & 0.051 & 10.6 & 0.79 & 14.7 & 24.8 \\
SA1 & NAMLITE-A & 0.102 & 0.133 & 0.051 & 1.94 & 0.92 & 2.7 & 7.3 \\
SA1 & MRTI-SA1-2 & 0.131 & 0.180 & 0.025 & 1.78 & 0.83 & 2.5 & 5.1 \\
Thin SA1 & NAMLITE-Th-2 & 0.101 & 0.134 & 0.051 & 1.83 & 0.83 & 2.5 & 6.9 \\
Thin SA1 & MRTI-Th-2 & 0.130 & 0.160 & 0.051 & 1.88 & 0.79 & 2.6 & 2.7 \\
7421 & MRTI-4-01 & 0.110 & 0.190 & 0.020 & 1.88 & 0.68 & 2.6 & 5.5 \\
FT-1H & LBNL982-1 & 0.060 & 0.156 & 0.025 & 2.25 & 0.74 & 3.0 & 9.0 \\
FT-2H & LLNL99Z-4 & 0.060 & 0.156 & 0.025 & 2.23 & 0.74 & 3.0 & 8.9 \\
Nano-1 & NAM-MgMethylate & 0.102 & 0.133 & 0.025 & 0.85 & 0.78 & 1.1 & 3.1 \\
3\% SiFe & MagMetals-1mil-1 & 0.083 & 0.114 & 0.038 & 1.01 & 0.77 & 1.4 & 4.6 \\
3\% SiFe & MagMetals-2mil-1 & 0.083 & 0.114 & 0.038 & 1.23 & 0.86 & 1.6 & 5.2 \\
3\% SiFe & MagMetals-4mil-1 & 0.083 & 0.114 & 0.038 & 1.31 & 0.92 & 1.7 & 5.5 \\
6\% SiFe & NorthStar-3 & 0.030 & 0.060 & 0.025 & 0.36 & 0.90 & 0.5 & 3.4 \\
\hline \hline
\end{tabular}


inner and outer diameters of the magnetic alloy windings, the width, the mass, the packing fraction $(\mathrm{PF}=$ ratio of the volume of metal to the geometrical core volume), and the core volume and area, corrected by the packing fraction to yield the equivalent solid metal volume and area. The measured parameters for each core are input to the analysis program that computes the flux swing and the core losses per unit volume.

The analysis program uses a sequence of command files that reads the data files, parses the descriptive text such as shot number, then reads the data channels. After baseline correcting all channels, the two current channels at different gains are spliced into one data record. We then find the peak voltage, averaged over $1 / 6$ of the pulse length (to average over ringing or overshoot at turn-on), and select data where the voltage is above $40 \%$ of the peak value for subsequent analysis. Rewriting Eq. (1), the flux swing $\Delta B$ is given by $\Delta B=\Sigma V d t / A_{c}$, where $d t$ is the digitizing interval between points. This value is computed for every data point in the shot. We interpolate to get exact flux swing intervals of $0.05 \mathrm{~T}$. The magnetization rate of a core is $d B / d t=V / A_{c}$ where $A_{c}$ is the net cross-sectional area, not the geometrical area, of the metal in the core, determined by the mass and volume of the core, corrected for the packing factor. The magnetization rate that we list is the average from the beginning of the pulse, until a given flux swing is reached. The energy loss $U$ in a core is

$$
U(\mathrm{~J})=\Sigma I V d t
$$

and

$$
u\left(\mathrm{~J} / \mathrm{m}^{3}\right)=U(\mathrm{~J}) / V_{c}
$$

where $V_{c}$ is the volume of amorphous metal, determined by weight and the manufacturer's published density, or equivalently, $V_{c}$ is the product of the packing factor times the geometrical volume.

These results - the time, the average magnetization rate $d B / d t$, the flux swing $\Delta B$, the integrated core loss, the voltage, and the current - are written into a separate file

TABLE II. Each amorphous metal core reported in this paper is listed with its alloy, its coating and individual label, flux swing, saturation magnetic field, the ratio of the remanent to saturation magnetic field measured for $d B / d t \approx 2 \mathrm{~T} / \mu \mathrm{s}$, the best fit coefficients

\begin{tabular}{|c|c|c|c|c|c|c|c|c|c|c|}
\hline Alloy & $\begin{array}{c}\text { Coating } \\
\text { label }\end{array}$ & $\Delta B(\mathrm{~T})$ & $B_{s}$ & $\frac{B_{r}}{B_{s}}$ & $C_{1}$ & $C_{2}$ & $C_{3}$ & $\begin{array}{c}\text { Loss } \\
\left(\mathrm{J} / \mathrm{m}^{3}\right) \\
5 \mu \mathrm{s}\end{array}$ & $\begin{array}{c}\text { Loss } \\
\left(\mathrm{J} / \mathrm{m}^{3}\right) \\
1 \mu \mathrm{s}\end{array}$ & $\begin{array}{c}\text { Loss } \\
\left(\mathrm{J} / \mathrm{m}^{3}\right) \\
0.2 \mu \mathrm{s}\end{array}$ \\
\hline \multirow[t]{2}{*}{$2605 \mathrm{SC}$} & Mica-12 & 2.25 & & & 31.11 & 293.6 & 109.2 & 245 & 623 & 1910 \\
\hline & & 2.40 & & & 39.32 & 301.1 & 115.1 & 289 & 740 & 2310 \\
\hline $2605 \mathrm{SC}$ & Mica-13 & 2.25 & & & 10.81 & 343.8 & 97.67 & 253 & 652 & 1940 \\
\hline \multirow[t]{2}{*}{$2605 \mathrm{SC}$} & Mica-14 & 2.25 & 1.69 & 0.685 & 24.69 & 299.6 & 67.45 & 228 & 550 & 1540 \\
\hline & & 2.40 & & & 41.75 & 294.1 & 68.00 & 266 & 628 & 1770 \\
\hline $2605 \mathrm{SC}$ & $\mathrm{NaSi}-01$ & 2.20 & 1.59 & 0.626 & 65.66 & 310.1 & 61.86 & 260 & 568 & 1490 \\
\hline \multirow{2}{*}{$2605 \mathrm{SC}$} & $\mathrm{NaSi}-02$ & 2.10 & 1.54 & 0.610 & -4.17 & 415.9 & 30.04 & 232 & 547 & 1350 \\
\hline & & 2.25 & & & 12.30 & 440.6 & 24.21 & 286 & 650 & 1560 \\
\hline $2 \mathrm{HCP}$ & NaSi-03-01 & 2.40 & 1.52 & 0.777 & -56.65 & 315.3 & 156.4 & 224 & 760 & 2720 \\
\hline $2 \mathrm{HCP}$ & NaSi-03-02 & 2.30 & 1.45 & 0.861 & 261.1 & 3.41 & 189.9 & 316 & 615 & 2100 \\
\hline 7421 & NaSi-04-01 & 2.00 & 1.55 & 0.440 & -138.5 & 585.4 & 185.6 & 233 & 789 & 2560 \\
\hline 7421 & NaSi-04-02 & 1.95 & 1.46 & 0.445 & 15.15 & 454.8 & 53.05 & 246 & 570 & 1430 \\
\hline \multirow[t]{3}{*}{1605 SA1 } & MgMethylate-thin & 2.20 & & & 38.08 & 255.7 & 299.6 & 285 & 878 & 3330 \\
\hline & & 2.50 & & & 14.05 & 364.6 & 245.7 & 395 & 1205 & 4370 \\
\hline & & 2.70 & & & -31.28 & 553.9 & 185.7 & 523 & 1530 & 5090 \\
\hline 2605 SA1 & NAMLITE-A & 2.60 & 1.68 & 0.797 & 360.8 & 44.47 & 10.44 & 414 & $\ldots$ & $\ldots$ \\
\hline 2605 SA1 & $\mathrm{NaSi}-01$ & 2.20 & 1.62 & 0.560 & -55.44 & 435.0 & 117.4 & 245 & 719 & 2220 \\
\hline 2605 SA1 & $\mathrm{NaSi}-02$ & 2.10 & 1.53 & 0.526 & 32.23 & 393.2 & 102.0 & 271 & 657 & 1850 \\
\hline 2605 SA1 & NaSi-pot-04 & 1.75 & 1.47 & 0.279 & 84.51 & 502.3 & 54.60 & 277 & 571 & 1330 \\
\hline SA1-thin & NaSi-pot-1 & 1.75 & 1.58 & 0.201 & 117.2 & 420.9 & 16.05 & 259 & 486 & 1020 \\
\hline SA1-thin & $\mathrm{NaSi}-2$ & 2.10 & 1.60 & 0.554 & 28.07 & 330.7 & 44.38 & 217 & 492 & 1250 \\
\hline SA1-thin & $\mathrm{NaSi}-3$ & 2.10 & 1.54 & 0.415 & 81.41 & 298.0 & 73.46 & 252 & 540 & 1420 \\
\hline SA1-thin & $\mathrm{NaSi}-4$ & 2.10 & 1.56 & 0.474 & 44.86 & 324.0 & 66.09 & 234 & 530 & 1410 \\
\hline SA1-thin & NAMLITE-3 & 2.15 & 1.55 & 0.713 & 341.4 & -866.0 & 1395 & 249 & 1420 & $\ldots$ \\
\hline SA1-thin & NAMLITE-oil-4 & 2.60 & 1.54 & 0.812 & -73.63 & 1592 & 176.7 & 1217 & 3090 & $\ldots$ \\
\hline SA1-thin & NAMLITE-oil-6 & 2.15 & 1.57 & 0.866 & 1163 & -3983 & 4398 & 153 & 2970 & $\ldots$ \\
\hline SA1-thin & NAMLITE-20 & 2.55 & 1.57 & 0.834 & -157.4 & 553.7 & 713.0 & 621 & 2630 & $\ldots$ \\
\hline SA1-thin & NAMLITE-21 & 2.55 & 1.56 & 0.804 & 66.89 & 273.1 & 248.1 & 399 & 1170 & $\ldots$ \\
\hline
\end{tabular}
to Eq. (4) for the listed flux swing, and the losses computed from Eq. (4) for three pulse durations. 
as an array at exact $0.05 \mathrm{~T}$ increments of flux swing. An associated command file can call this routine repeatedly to analyze a sequence of shots with one core. Error traps enable missing shots to be skipped.

A second command file opens the data files for each of a sequence of shots, selects data at an interval chosen (usually $0.5 \mathrm{~T}$ ), and writes the selected data for the entire sequence to a file. This file is opened by a third command file that makes plots of the core loss versus magnetization rate at the selected flux swing intervals up to the maximum and also plots the maximum flux swing versus the magnetization rate. This latter plot, along with the tabular data file written by the second command file, is useful in finding bad shots that can then be deleted from the sequence and the second and third command files rerun. Variants of the second and third command files allow selecting the flux swing, to be plotted, in $0.05 \mathrm{~T}$ increments, as used in this paper.

Core losses account for most of the pulsed energy losses in an induction linac, so minimizing the core loss decreases the capital costs of pulsers and increases the accelerator efficiency. In the third command file, core losses, per cubic meter of core, are fitted by a three-term function proposed by Smith $[14,24]$

$$
\begin{aligned}
u\left(\mathrm{~J} / \mathrm{m}^{3}\right)= & C_{1}\left(\frac{\Delta B}{2.5}\right)+C_{2}\left(\frac{\Delta B}{2.5}\right)\left(\frac{d B}{d t}\right)^{0.5} \\
& +C_{3}\left(\frac{\Delta B}{2.5}\right)^{2}\left(\frac{d B}{d t}\right)
\end{aligned}
$$

where $\Delta B$ is in Tesla, $d B / d t$ is in $\mathrm{T} / \mu \mathrm{s}$, and the coefficients are listed in Tables II and III for each core. The first term represents the energy to magnetize the alloy at low magnetization rates. The second term represents the energy to magnetize bar domains (that cut across the tape) at moderate magnetization rates. The third term represents the energy to magnetize sandwich domains (that encircle the tape) at high magnetization rates. We find that this function fits the losses of most cores well, but the coefficients vary with flux swing for each core, as discussed in Sec. IV.

We determine the usable flux swing as shown in Fig. 2. We draw one straight line through the flattop of the voltage pulse and a second straight line to approximate the initial voltage sag approaching saturation. We define the usable flux swing to be at the duration of $\Delta t$ where the measured voltage departs from the sloped line. The assumption here is that we use either a tapered impedance pulse-forming

TABLE III. Each nanocrystalline or silicon-steel core reported in this paper is listed with its alloy, its coating and individual label, flux swing, saturation magnetic field, the ratio of the remanent to saturation magnetic field measured for $d B / d t \approx 2 \mathrm{~T} / \mu \mathrm{s}$, the best fit coefficients to Eq. (4)for the listed flux swing, and the losses computed from Eq. (4)for three pulse

\begin{tabular}{|c|c|c|c|c|c|c|c|c|c|c|}
\hline Alloy & $\begin{array}{c}\text { Coating } \\
\text { label }\end{array}$ & $\Delta B(\mathrm{~T})$ & $B_{s}$ & $\frac{B_{r}}{B_{s}}$ & $C_{1}$ & $C_{2}$ & $C_{3}$ & $\begin{array}{c}\text { Loss } \\
\left(\mathrm{J} / \mathrm{m}^{3}\right) \\
5 \mu \mathrm{s}\end{array}$ & $\begin{array}{c}\text { Loss } \\
\left(\mathrm{J} / \mathrm{m}^{3}\right) \\
1 \mu \mathrm{s}\end{array}$ & $\begin{array}{c}\text { Loss } \\
\left(\mathrm{J} / \mathrm{m}^{3}\right) \\
0.2 \mu \mathrm{s}\end{array}$ \\
\hline FT-1H & $\mathrm{SiO}_{2}-\mathrm{LBNL}-1$ & 2.10 & 1.26 & 0.831 & 37.83 & -2.41 & 163.3 & 78.9 & 271 & 1235 \\
\hline FT-1H & $\mathrm{SiO}_{2}-\mathrm{LBNL}-2$ & 2.05 & 1.30 & 0.775 & 28.08 & 12.99 & 157.7 & 73.3 & 256 & 1144 \\
\hline FT-1H & $\mathrm{SiO}_{2}-\mathrm{LBNL}-3$ & 2.05 & 1.26 & 0.788 & 22.62 & 36.22 & 136.7 & 75.3 & 250 & 1056 \\
\hline FT-1H & $\mathrm{SiO}_{2}-\mathrm{LBNL}-3$ & 2.00 & 1.25 & 0.761 & -46.70 & 190.0 & 71.62 & 77.1 & 269 & 902 \\
\hline \multirow[t]{2}{*}{ FT-2H } & $\mathrm{SiO}_{2}-99 \mathrm{Z}-1$ & 2.25 & 1.37 & 0.705 & 19.07 & 166.8 & 63.66 & 141 & 358 & 1101 \\
\hline & & 2.00 & & & 24.68 & 106.3 & 77.6 & 93.4 & 239 & 785 \\
\hline FT-2H & $\mathrm{SiO}_{2}-99 \mathrm{Z}-2$ & 2.25 & 1.37 & 0.735 & 28.94 & 124.9 & 75.14 & 129 & 332 & 1088 \\
\hline FT-2H & $\mathrm{SiO}_{2}-99 \mathrm{Z}-3$ & 2.25 & 1.36 & 0.749 & 29.53 & 118.5 & 78.19 & 127 & 329 & 1097 \\
\hline FT-2H & $\mathrm{SiO}_{2}-99 \mathrm{Z}-4$ & 2.00 & 1.36 & 0.814 & 39.48 & 45.56 & 89.77 & 77.6 & 198 & 721 \\
\hline FT-1H & & 2.40 & & & 33.13 & 111.2 & 71.35 & 137 & 355 & 1191 \\
\hline Vitroprm & Meth-1 & 2.15 & 1.28 & 0.875 & -9.158 & 68.75 & 99.53 & 62.5 & 237 & 977 \\
\hline $500 \mathrm{~F}$ & & 2.25 & & & -17.71 & 86.94 & 95.68 & 71.4 & 276 & 1118 \\
\hline VP 500F & Meth-2 & 2.15 & & & 32.59 & 31.43 & 101.2 & 77.9 & 229 & 921 \\
\hline VP 500F & Meth-3 & 2.10 & & & -1.757 & 50.62 & 102.8 & 56.6 & 212 & 898 \\
\hline \multirow[t]{3}{*}{$3 \% \mathrm{SiFe}$} & MM-P3301-1 & 3.00 & 1.90 & 0.753 & 279.7 & 372.7 & 189.5 & 846 & 1930 & 6160 \\
\hline & MM-P3301-2 & 3.00 & & & 356.7 & 174.0 & 261.6 & 816 & 1920 & 6890 \\
\hline & MM-P3301-3 & 3.00 & & & 349.2 & 230.1 & 254.3 & 853 & 2000 & 6980 \\
\hline $3 \% \mathrm{SiFe}$ & MM-P3302-1 & 3.30 & 1.98 & 0.835 & 92.83 & 486.5 & 902.8 & 1680 & 6480 & 28690 \\
\hline $3 \% \mathrm{SiFe}$ & MM-P3304-1 & 3.20 & 1.84 & 0.840 & 10270 & -23550 & 16680 & 6520 & 46690 & 329900 \\
\hline $3 \% \mathrm{SiFe}$ & MM-P3404-1 & 3.30 & & & 616.1 & -1776 & 6188 & 6020 & 32130 & 169200 \\
\hline $6 \% \mathrm{SiFe}$ & NorthStar-2 & 2.40 & 1.81 & 0.661 & 178.0 & 459.0 & 822.3 & 840 & 2670 & 10790 \\
\hline $6 \% \mathrm{SiFe}$ & NorthStar-3 & 2.40 & 1.89 & 0.648 & 243.2 & 373.1 & 871.2 & 867 & 2720 & 11110 \\
\hline $6 \% \mathrm{SiFe}$ & NorthStar-4 & 2.40 & 1.77 & 0.670 & 311.7 & 533.8 & 831.8 & 1020 & 2930 & 11270 \\
\hline
\end{tabular}
durations. 
network or two simple pulsers to yield an extended flattop-a square pulse plus a ramped pulse that flattens the drooping portion of the pulse, thereby increasing the usable pulse duration further into saturation.

We measure the remanent and saturation fields by means of two successive shots. After the first "normal" shot, we turn the reset circuit off, disconnect its trigger, and reverse the polarity of both the primary and secondary windings on the core before taking the second shot. The first shot takes the core from $-B_{r}$ to $+B_{s}$, and the ringback returns the core to $-B_{r}$. The second shot starts at the same point with a reset core, $-B_{r}$, but takes the core in the opposite direction to $-B_{s}$. Data for two contrasting cores are shown in Fig. 4. In Fig. 4(a), data for a nanocrystalline core, with an exceptionally square $B-H$ loop, are shown ("square" means that the ratio of $B_{r}$ to $B_{s}$, approaches unity, in this case, 0.86). The most frequent degradation from mechanical stress on a core is that the remanent field is reduced, while the saturation field is unaffected, Fig. 4(b) [10]. In this case, an SA1 core was coated with a material that normally results in a ratio $B_{r} / B_{s}=0.5-0.6$, but after potting the core in $\sim 500 \mu \mathrm{m}$ of silicon rubber, the ratio decreased to 0.20 . With optimum insulation and anneal, the ratio of the remanent to the saturation field can reach $0.85-0.90$, as we observed in Fig. 4(a), whereas it may be 0.50 or lower if the insulation applies significant stress to the alloy.

We also did limited investigations of backbiasing cores, either with a dc current, through a large inductor $(\sim 4 \mathrm{mH})$ to protect the dc power supply from the pulse [7], or by varying the delay between the reset pulse and the main pulse, so that the main pulse occurred before the reset current had decayed to zero [25]. As with the other work reported here, we were generally seeking low losses. For example, with a $5 \mathrm{~Hz}$ pulser we used the highest flux swing that could be achieved with little increase in the primary current magnitude at the beginning of the pulse and with the primary current rising by less than a factor of 2 by the end of the pulse. This resulted in slightly higher flux swings for some alloys, but lower for others (5\%-10\% higher for FT-1H, 0\%-5\% higher for MRTI-SA1, and 7\% lower for $1 \mathrm{mil} 3 \% \mathrm{SiFe}$ [7]). In another example, we found that small gains in flux swing of 5\%-8\% could be achieved at the expense of an increase in the coefficients of Eq. (4) by about $10 \%$ [25]. The drive current must overcome the bias current before $H$ can change in the core; therefore, we expect increased drive current and losses as the bias current is increased.

Larger gains in flux swing are available from backbiasing if low core losses are not required. An example is shown in Fig. 5, for a core manufactured by Moscow Radio Technical Institute (MRTI) [16] using a Russian alloy 7421 with a remanent field that is only $44 \%$ of the saturation field, Table II. As before, a small increase in flux swing is possible with a small increase in loss. With a larger backbias current, the flux swing increases by a factor of up to 1.5 , from 1.8 to $2.7 \mathrm{~T}$; however, the losses
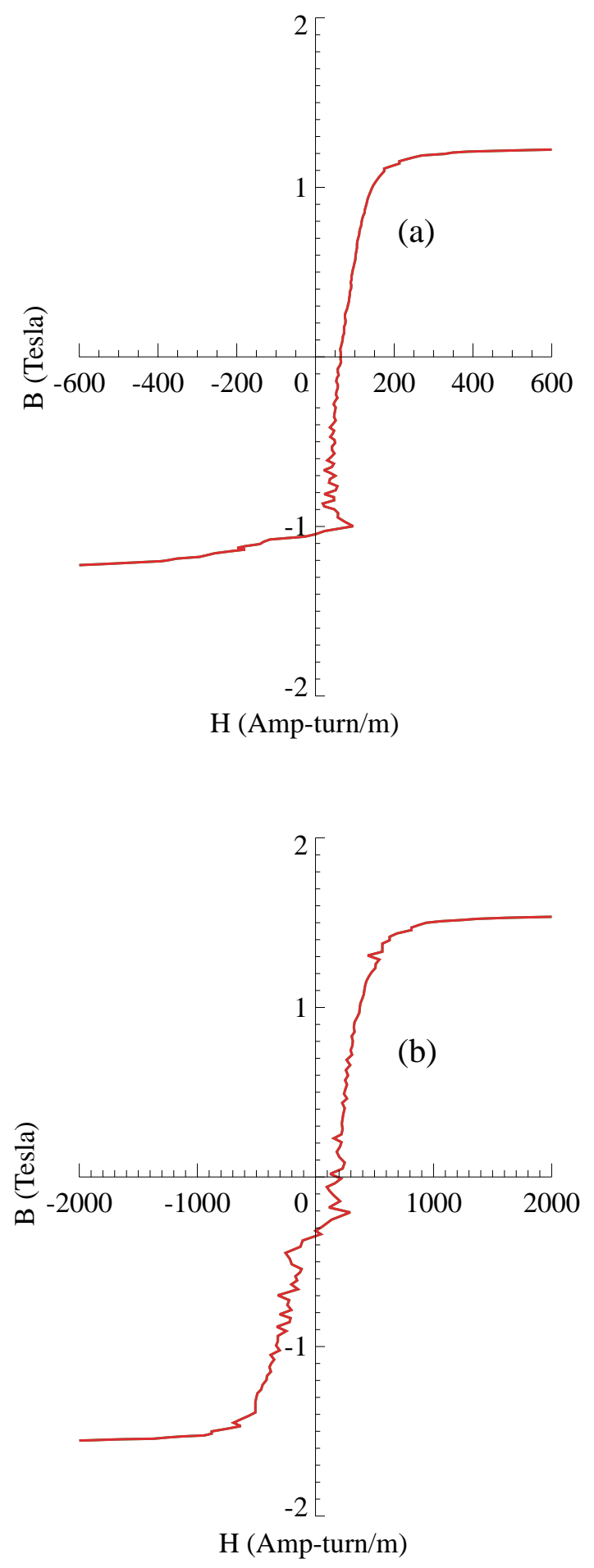

FIG. 4. (Color) (a) A partial $B-H$ loop for a VITROPERM nanocrystalline core, manufactured by National Arnold Magnetics, exhibits a high remanent field. (b) Potting a METGLAS 2605 SA1 core reduces the remanent field.

increase by a factor of up to 4 , from 0.5 to $2 \mathrm{~kJ} / \mathrm{m}^{3}$ at a magnetization rate of $2.2 \times 10^{6} \mathrm{~T} / \mathrm{s}$. Backbiasing gives the largest increases in usable flux swing for cores with low remanent fields, such as this one. 


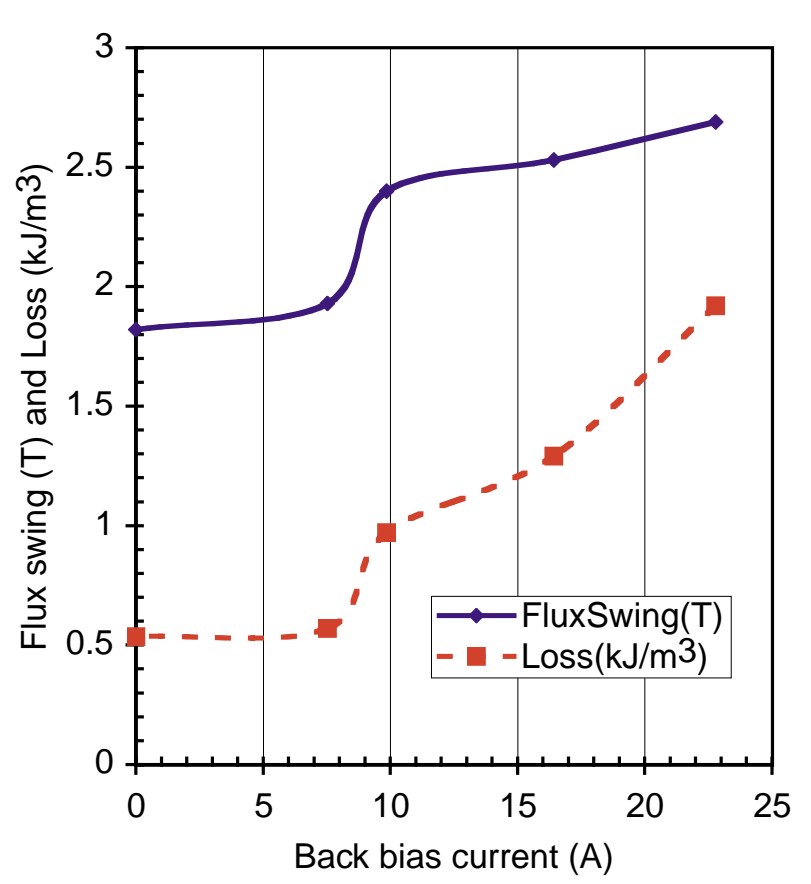

FIG. 5. (Color) Flux swing ( $\diamond$, blue, solid line) and core loss ( $\square$, red, dashed line) both increase with backbias current for MRTI core 04-02, alloy 7421.

\section{ALLOYS STUDIED}

\section{A. Alloy summary}

Low core losses require winding with tapes that have a thickness of $\leq 25 \mu \mathrm{m}$. Before 1980, such materials, e.g., silicon steel, were obtained by successive rolling of steel tape to thinner cross sections between hardened steel rollers. Around 1980, the spin-casting technique was developed for making amorphous metal tape by extruding molten metal onto a rapidly spinning cooled wheel. The tapes are amorphous because they solidify too rapidly for crystallization to occur. The requirement of rapid cooling limits the thickness to $\sim 25 \mu \mathrm{m}$, and uniform, highquality tapes are available down to $\sim 15 \mu \mathrm{m}$. In addition to a lower cost of manufacturing, these alloys tend to have resistivities of 2-4 times those of polycrystalline magnetic alloys, which results in lower eddy-current losses [14]. Nanocrystalline alloys are cast as amorphous alloys, but with the addition of $1 \%$ copper and a few percent of a metal such as niobium. These limit the growth of crystals to a $10 \mathrm{~nm}$ scale during subsequent heat treatment [21].

The performance of two varieties from each of the classes of alloys studied is summarized in Fig. 6. The displayed magnetization rates of $10^{5}-10^{7} \mathrm{~T} / \mathrm{s}$ cover most of the range of pulse durations needed in an HIF power-plant driver. The data shown include operation with pulses as long as $20-35 \mu \mathrm{s}$ which are appropriate for the injector in our present designs. To minimize the mass of cores needed to accelerate the beams to the final energy, the beam duration is decreased, as the beam energy increases,

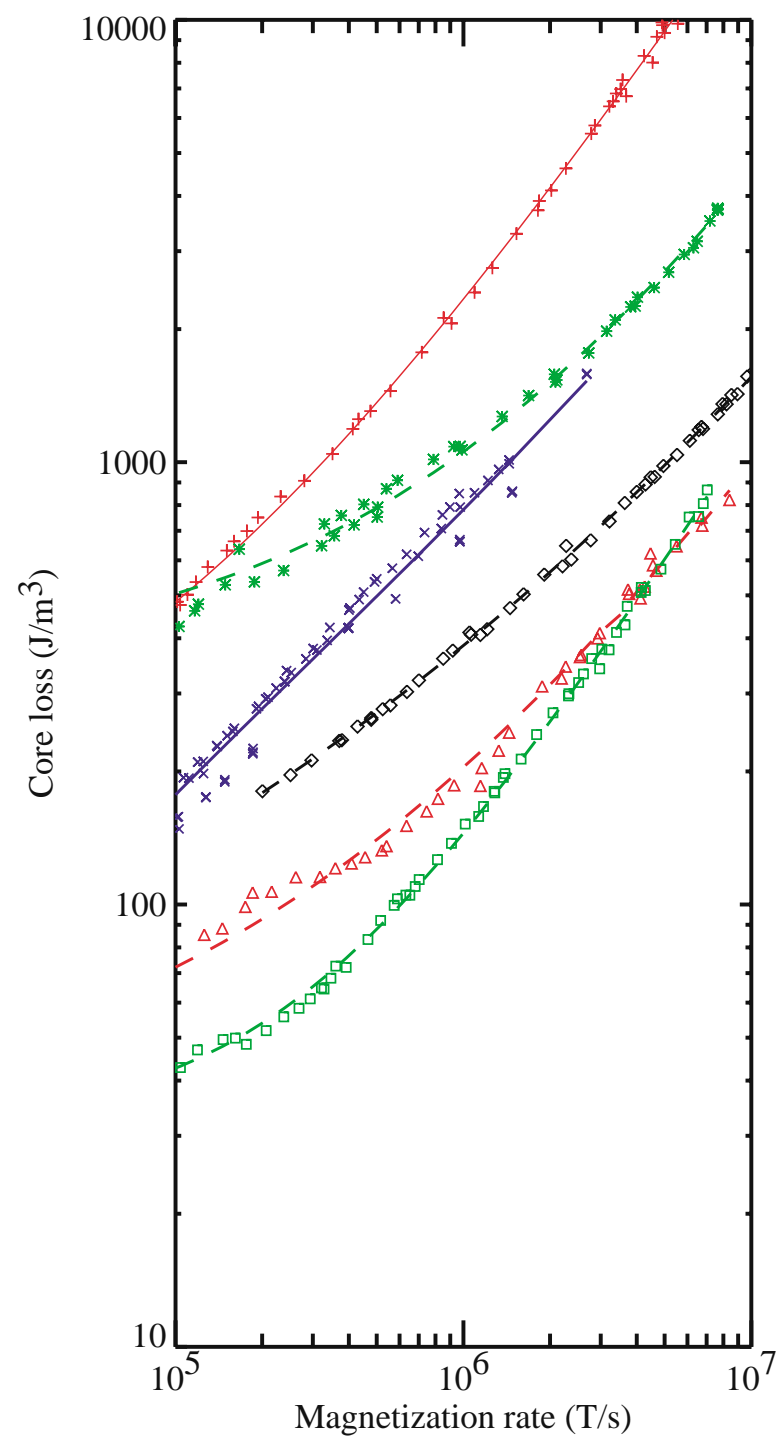

FIG. 6. (Color) Core loss versus magnetization rate for six cores, all annealed after winding. From the top, these are $(+$, red, solid line) $50 \mu \mathrm{m}$ thick $3 \%$ silicon steel with $\Delta B=3.3 \mathrm{~T}$; (*, green, dashed line) $25 \mu \mathrm{m}$ thick $3 \%$ silicon steel with $\Delta B=3.0 \mathrm{~T}$; ( $\times$, blue, solid line) METGLAS 2605 SA1 with magnesium methylate insulation with $\Delta B=2.7 \mathrm{~T}$; ( $\diamond$, black, dashed line) METGLAS 2605 SC cowound with mica paper insulation with $\Delta B=2.4 \mathrm{~T}$; $(\triangle$, red, dashed line) FINEMET FT-2H with $\Delta B=2.4 \mathrm{~T}$; and ( $\square$, green, dashed line) FINEMET FT-1H with $\Delta B=2.1 \mathrm{~T}$. Both FINEMET alloys are insulated with a glass coating.

as rapidly as is permitted by the beam-transport current limits. We reduce the total mass of induction cores by minimizing the total core area in an accelerator, but since the core area determines the volt seconds, we prefer to get as many "volts" as possible by minimizing the "seconds" in each case. The shortest pulse durations corresponding to $10^{7} \mathrm{~T} / \mathrm{s}$ are $200-350 \mathrm{~ns}$, which are in the range presently considered for most of the driver-accelerator length.

We summarize our measurements of the performance of each core that we tested in Tables II and III. The first 
two columns list the alloy, the type of insulation (a coating except for a few cores insulated with cowound mica paper interlaminar insulation), and a core identification number or label. The remaining columns list our measured values for the usable flux swing, the saturation magnetic field, the ratio of the remanent to the saturation field, the three coefficients from Eq. (4) used to fit the core losses versus the magnetization rate, and finally the core losses for pulse durations of 5.0, 1.0, and $0.2 \mu \mathrm{s}$, respectively. These are representative of pulse durations from near the injector to the high energy region of an HIF driver.

In some cases, a single core has been evaluated at more than one flux swing, either to allow comparing with a different alloy at a common flux swing or because we used different criteria for usable flux swing. In these cases, we notice that the core losses increase with flux swing as expected. However, the coefficients used to fit core loss do not vary in a simply predictable manner; therefore these coefficients are not usable with different flux swings, even though the model includes flux swing as one of the parameters that must be fit. We compared core losses for a METGLAS 2605 SA1 core [16] and for a FINEMET FT-2H core [16], and found that applying the coefficients from one value of flux swing to another led to errors. For changes in flux swing of $\leq 0.1 \mathrm{~T}$, the errors were less than $10 \%$ for each of these two cores. However, as the difference in flux swings increased to $0.4-0.5 \mathrm{~T}$, the errors became as large as $+39 \%$ and $-23 \%$. The implication is that the bar and sandwich domain model [14], used for the fit, does not include all of the relevant physics. As can be seen from the data plots to follow, Eq. (4) generally provides a good fit to core loss as a function of $d B / d t$ for a given flux swing, but the discussion above demonstrates that it is not reliable for different flux swings than were fit.

The highest loss material, that could be usable for HIF power plants, is 3\% silicon steel in either $50 \mu \mathrm{m}$ thickness, which yielded a $3.3 \mathrm{~T}$ flux swing, or $25 \mu \mathrm{m}$ thickness, which yielded a $3.0 \mathrm{~T}$ flux swing. We also evaluated $3 \%$ silicon steel with a thickness of $100 \mu \mathrm{m}$, for which we judged the losses unacceptable. These flux swings are higher than with the amorphous materials, which allow reducing the size of the cores. If the $3 \%$ silicon steel is restricted to longer pulse duration applications near the injector, the total increase in time-averaged pulser power to drive the cores can be well under $1 \mathrm{MW}$ (out of a few tens of megawatts average-pulser power in a power plant), determined by applying the model used in Ref. [7]. For example, we could use $50 \mu \mathrm{m} 3 \%$ silicon steel with a flux swing of $3.3 \mathrm{~T}$, rather than the $2.7 \mathrm{~T}$ that is achievable with $\mathrm{SA} 1$, to increase the beam energy from 2 to $33 \mathrm{MeV}$. This would result in a core mass reduction of $820000 \mathrm{~kg}$ and an increase in pulser power of $620 \mathrm{~kW}$ at a repetition rate of $5 \mathrm{~Hz}$; see Table IV.

Amorphous materials, represented by METGLAS 2605 SA1 and 2605 SC form the middle group. We achieved flux swings of 2.7 and $2.25 \mathrm{~T}$, respectively. These flux
TABLE IV. Simple model of the low energy end of a powerplant driver. The higher flux swing of $3 \%$ silicon steel reduces the mass of induction cores by 130-800 tons, at the expense of increasing the pulser power (for $5 \mathrm{~Hz}$ operation) by $0.18-0.62 \mathrm{MW}$. For pulse durations decreasing to $10 \mu \mathrm{s}$, the ion energy increases from 2 to $4 \mathrm{MeV}$; for durations to $5 \mu \mathrm{s}$, the beam energy increases to $8 \mathrm{MeV}$; and for durations to $2 \mu \mathrm{s}$, the beam energy increases to $33 \mathrm{MeV}$.

\begin{tabular}{lcccc}
\hline \hline \multicolumn{1}{c}{ Alloy } & $\begin{array}{c}\Delta B \\
(\mathrm{~T})\end{array}$ & $\begin{array}{c}\Delta t \\
(\mu \mathrm{s})\end{array}$ & $\begin{array}{c}\text { Power } \\
(\mathrm{MW})\end{array}$ & $\begin{array}{c}\text { Mass } \\
\left(10^{3} \mathrm{~kg}\right)\end{array}$ \\
\hline 3\% SiFe 25 $\mu \mathrm{m}$ & 3.0 & $20-10$ & 0.31 & 880 \\
3\% SiFe 50 $\mu \mathrm{m}$ & 3.3 & $20-10$ & 0.30 & 790 \\
2605 SA1 & 2.7 & $20-10$ & 0.12 & 920 \\
3\% SiFe 25 $\mu \mathrm{m}$ & 3.0 & $20-5$ & 0.70 & 1850 \\
3\% SiFe 50 $\mu \mathrm{m}$ & 3.3 & $20-5$ & 0.79 & 1660 \\
2605 SA1 & 2.7 & $20-5$ & 0.33 & 1930 \\
3\% SiFe 25 $\mu \mathrm{m}$ & 3.0 & $20-2$ & 0.87 & 5520 \\
3\% SiFe 50 $\mu \mathrm{m}$ & 3.3 & $20-2$ & 1.06 & 4940 \\
2605 SA1 & 2.7 & $20-2$ & 0.44 & 5760 \\
\hline \hline
\end{tabular}

swings are sufficiently large, the losses are sufficiently low, and the production costs are anticipated to be low, so these materials appear to be attractive for the bulk of an HIF driver. Accounting only for core losses, the acceleration efficiency slightly exceeds $50 \%$ for pulses shorter than $1 \mu \mathrm{s}$, in a $3.3 \mathrm{MJ}, 1.3 \mathrm{GeV} \mathrm{Kr}^{+}$driver [7]. (The acceleration efficiency would be lower if one made a more conservative choice of a heavier ion than krypton which would not require as high a degree of neutralization to focus to a small spot size on the target.) The difference in the flux swings between 2605 SA1 and 2605 SC is believed to represent differences in the coatings and processing that affect the remanent magnetic field, rather than differences in the magnetic alloys, which should perform more similarly. This will be discussed in more detail in Sec. V. (As shown in Fig. 5, higher flux swings can be obtained, even with as-cast $2605 \mathrm{SC}$, if high efficiency acceleration is not required. For example, $2.7 \mathrm{~T}$ flux swings have been achieved with $\pm 600 \mathrm{~A} / \mathrm{m}$ of drive [26].)

Nanocrystalline materials, represented by FINEMET FT-2H and FT- $1 \mathrm{H}$, form the lowest loss group. The flux swings are $2.25-2.4$ and $2.0-2.1 \mathrm{~T}$, respectively. This material would be most useful for applications where the pulser costs exceed the core costs. An example of this is a high-precision feedback-controlled correction pulser [8]. Another example is studying the effects (on pulser operation and beam dynamics) of a higher ratio of the beam current to the core magnetization current in near-term experiments with from one to a few beams that have much lower total-beam current than fusion drivers with the order of 100 parallel beams. During the beam pulse, the pulser must supply the sum of the beam current plus the core magnetization current. If the beam current significantly increases the pulser current, care will be required to avoid perturbations of the pulser waveform and the beam dynamics. The time-dependent drive current, 
Fig. 3(b), not only averages several times lower than with amorphous alloys, but it starts even lower, then increases monotonically by a factor of about 2 before the rapid increase at saturation. This behavior allows larger ratios of beam current to core drive current to be achieved, especially during the early part of a pulse.

We have reasonable success in fitting the flux swing with the measured parameters $B_{s}$ and $B_{r}$ :

$$
\Delta B_{\mathrm{fit}}=B_{r}+C_{0} B_{s} .
$$

Solving for the coefficient $C_{0}$, we find the average is $C_{0}=0.81 \pm 0.10$ (standard deviation). (Others have found $C_{0} \sim 1.0$ [12].) In Fig. 7, we plot $\Delta B_{\text {fit }}$ versus the measured $\Delta B$. The predicted flux swing agrees with the computed flux swing with a standard deviation of $10 \%$. To check whether there was a nonlinear dependence on the squareness ratio $B_{r} / B_{s}$, we also plotted the error in the fit versus $B_{r} / B_{s}$. The results show no consistent slope that could be corrected by a nonunity exponent on $B_{r} / B_{s}$. We conclude that Eq. (5) provides a useful, approximate guide to the effect of variations in $B_{r}$ and $B_{s}$ on flux
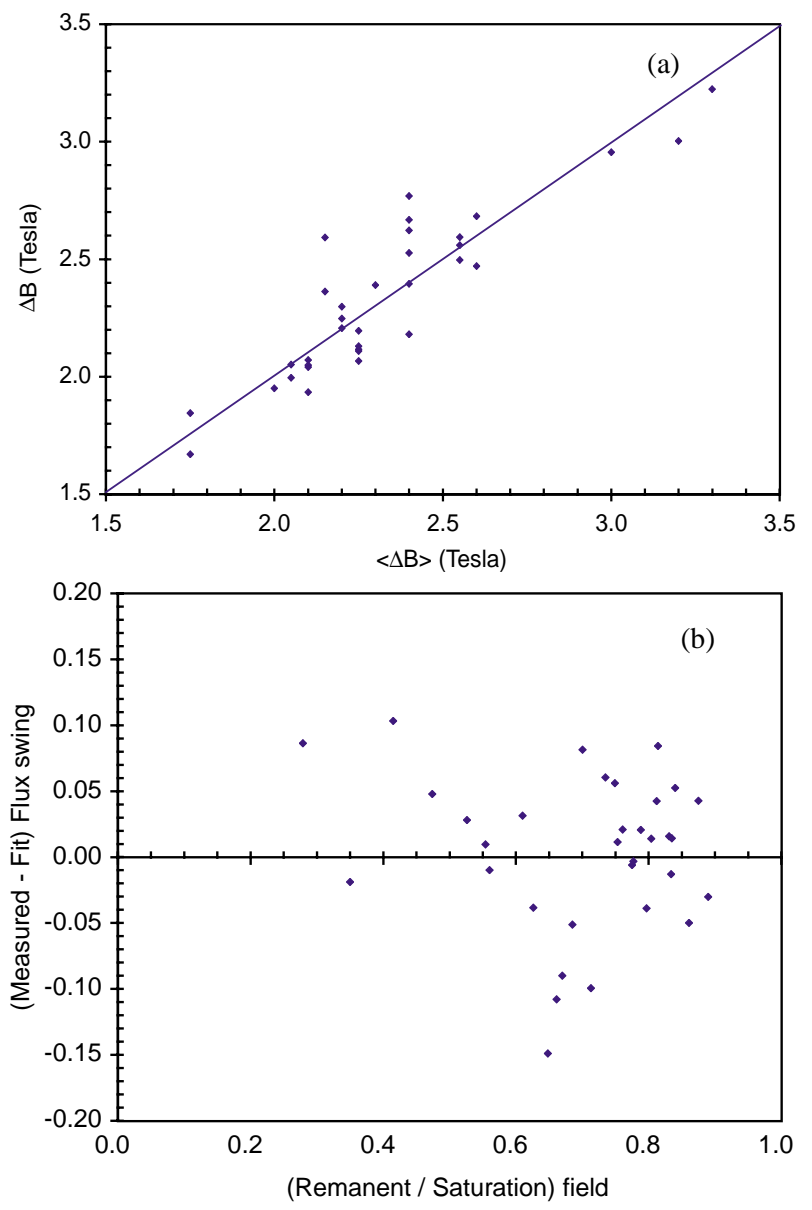

FIG. 7. (Color) (a) Flux swing from Eq. (5) versus the measured flux swing, data from Tables II and III. (b) Difference between measured and Eq. (5) flux swing versus the ratio of the remanent to saturation magnetic field. swing. Implicit in the use of Eq. (5) is the assumption that high acceleration efficiency is necessary, so that we start a pulse with the core near $-B_{r}$ [25]. If efficiency is not a high priority, then backbiasing with a large current can result in a flux swing that is $80 \%-90 \%$ of $2 B_{s}$, even with a material where $B_{r} / B_{s}$ approaches zero; see Fig. 5 and Ref. [26].

In the remainder of this paper, we will look at each alloy in more detail, as well as a few alternative alloys, in some cases with various coatings. We will investigate the reproducibility of cores with similar processing, the variation in the ratio of remanent field to saturation field, and its effect on flux swing with various coatings.

\section{B. Amorphous alloys}

METGLAS 2605 SC has been the traditional alloy of choice for HIF, based on its relatively low loss and high flux swing of 2.0-2.7 $\mathrm{T}$ [9]. To obtain the possible range of benefits from annealing, we first studied this material by winding $1-2 \mathrm{~kg}$ cores that had interlaminar insulation provided by cowound capacitor grade mica paper $[10,15]$. This insulation allowed winding cores that could be tested both before and after annealing, without embarking on a program to develop suitable coatings. This provided an expeditious method to reevaluate annealed versus as-cast cores with a mass $\gg 0.03 \mathrm{~kg}$, even though it had no future in the HIF program because the cost of mica paper and the maximum packing fraction of 0.46 (with tightly wound $16 \mu \mathrm{m}$ thick, $0.05 \mathrm{~m}$ wide $2605 \mathrm{SC}$, and $19 \mu \mathrm{m}$ thick mica paper; $13 \mu \mathrm{m}$ mica paper is available at higher cost) would be unacceptable for HIF drivers. As previously reported, we found that the flux swing increased after annealing only if we wound with a very low tension, $\leq 2.5 \mathrm{Nt}$ [15]. This resulted in "pillowy" cores with a packing fraction of only 0.20 . Such cores showed a dramatic improvement in performance with annealing, as shown in Fig. 2, similar to findings in earlier studies [9,10]. After magnetic anneal, the flattop portion of the voltage around the core increased by a factor of 2 or more, while the drive current actually decreased until the core approached saturation.

Fairly consistent performance was attained with the mica paper insulated $2605 \mathrm{SC}$ cores. The core loss versus magnetization rate is shown for three such cores in Fig. 8, two of the cores had losses within $8 \%$ or less, the largest difference on the third was $20 \%$, all at a flux swing of $2.25 \mathrm{~T}$. Two of the cores were usable at $2.4 \mathrm{~T}$ as shown in Fig. 9, with only a $12 \%$ increase in core losses.

A comparison of a mica paper insulated core with two coated cores is shown in Fig. 10. The coated cores were manufactured by MRTI, coated with modified sodium silicate, then wound and annealed [18]. All of these cores had similar flux swings of $2.20-2.25 \mathrm{~T}$. The two coated cores showed similar losses, within $12 \%$, while the losses for the mica paper core were lower by as much as $25 \%$ at low magnetization rates. From Table II, we see that 


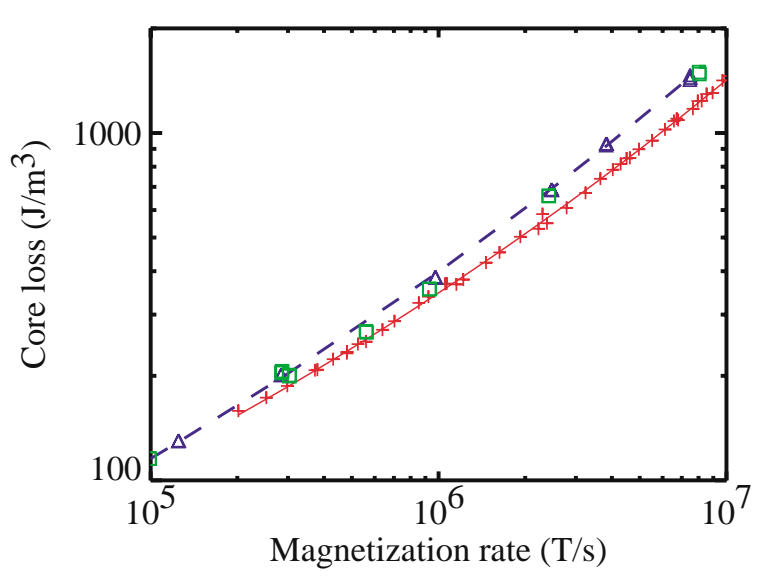

FIG. 8. (Color) Core loss versus magnetization rate for three METGLAS 2605 SC cores, all insulated with cowound mica paper and annealed after winding. The data are for a flux swing of $2.25 \mathrm{~T}(\square$, green) $\mathrm{C} 12,(\triangle$, blue, dashed line) $\mathrm{C} 13$, and $(+$, red, line) $\mathrm{C} 14$.

the ratio of $B_{r}$ to $B_{s}$ was $0.6-0.7$. Based on the alloy manufacturers data, the saturation field of $2605 \mathrm{SC}, 1.61 \mathrm{~T}$, should allow flux swings in the range of 2.45-2.75 $\mathrm{T}$ for $B_{r} / B_{s}=0.8$, Eq. (5), where the range is increased by the measured $10 \%$ standard deviation. Therefore, higher usable flux swings than the 2.25-2.40 T that we obtained should be achievable in 2605 SC cores with continued development of coating and annealing technology.

The sensitivity of coated cores to winding tension was explored with cores manufactured by MRTI using $0.021 \mathrm{~m}$ wide $2 \mathrm{HCP}$ (a Russian amorphous alloy evaluated in Ref. [11]). This study was motivated by the previously found sensitivity of mica paper insulated cores to winding tension [15]. To compare with the Ref. [15] mica paper results, we convert English units to SI and divide the Ref. [15] tension by 2.4 to normalize the tape width to $0.021 \mathrm{~m}$. The converted and normalized data show an improved performance after annealing only for winding tensions of 0.4 and $1 \mathrm{~N}$, and no improvement

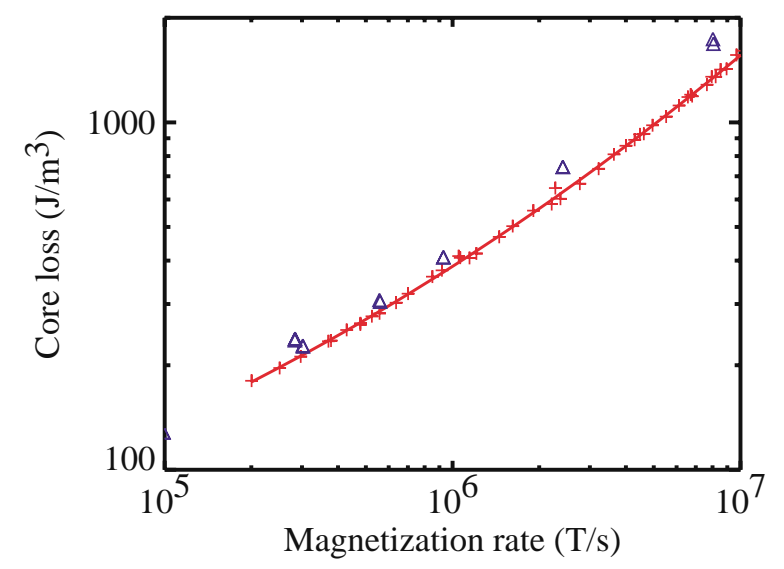

FIG. 9. (Color) Core loss versus magnetization rate for two METGLAS 2605 SC cores, The data are for a flux swing of $2.4 \mathrm{~T}(\triangle$, blue) $\mathrm{C} 12$ and $(+$, red, line) $\mathrm{C} 14$.

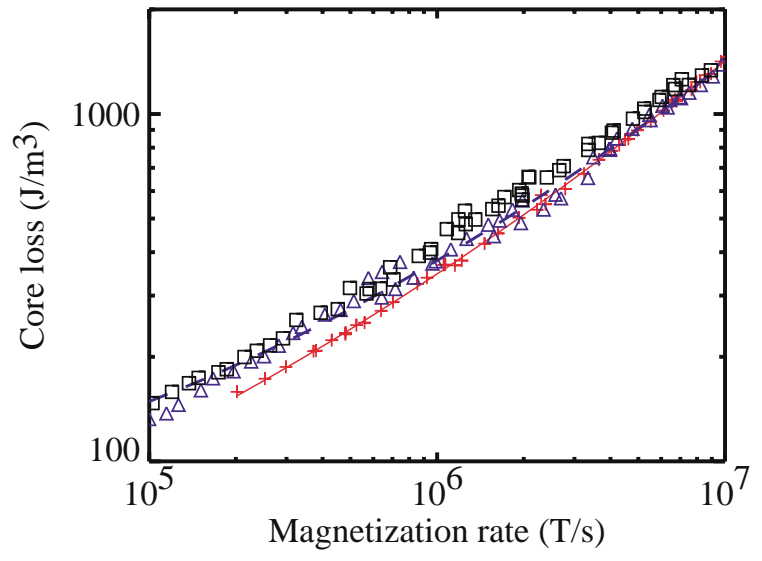

FIG. 10. (Color) Core loss versus magnetization rate for three METGLAS 2605 SC cores, The data are for the listed flux swings: ( $\square$, black) MRTI SC-02 at $2.25 \mathrm{~T}$; $(\triangle$, blue, dashed line) MRTI SC-01 at $2.20 \mathrm{~T}$; and (+, red, line) Mica-C14 at $2.25 \mathrm{~T}$.

after annealing for 5 and $10 \mathrm{~N}$ winding tension with mica paper. At MRTI, the winding tension was varied between 1 and $23 \mathrm{~N}$. No consistent variation with winding tension was seen in $B_{s}, B_{r} / B_{s}$, or $H_{c}$ (the current required to magnetize the core) at magnetization rates of 6 and $10 \times 10 \mathrm{~T} / \mathrm{s}$. The packing fraction was constant at $\sim 0.74$ and independent of tension above $15-20 \mathrm{~N}$. At lower tensions, the packing fraction was less reproducible, decreasing to as little as 0.64 at $1 \mathrm{~N}$. This indicates that winding tension is less critical with coated cores. Satisfactory tensions range from similar magnitude to that used successfully with mica paper to a factor of $\sim 20$ higher, and the maximum winding tension used was insufficient to degrade magnetic performance. The high packing fractions found with coated cores, Table I, are also consistent with high winding tension being allowable.

Slightly different results of varying winding tension have been previously reported for dc measurements with a different alloy, METGLAS 2605S-2 in a slightly wider ribbon, $0.025 \mathrm{~m}$ [27]. They found similar variations in the packing fraction and a similar lack of variation in $H_{c}$; however they found that the remanent field decreased for winding tensions of $15 \mathrm{~N}$ and above. ac loss measurements up to $100 \mathrm{~Hz}$ showed no effect from varying the winding tension of coated cores.

An alternative to annealing after winding is to anneal prior to winding into a core. This has been examined previously $[9,10]$ and it was found that $2605 \mathrm{SC}$ cores that have been rewound after anneal lose $20 \%-25 \%$ of their flux swing capability. (In the same references, another alloy, METGLAS $2605 \mathrm{CO}$, was found to have very little degradation after rewinding.) We purchased one set of cores that were rewound after annealing. These had inner and outer diameters of 0.324 and $0.426 \mathrm{~m}$, respectively and a width of $0.025 \mathrm{~m}$. The manufacturer reported that this batch lost from $45 \%$ to $60 \%$ of its dc flux swing during the rewinding process after annealing, so the dc performance 


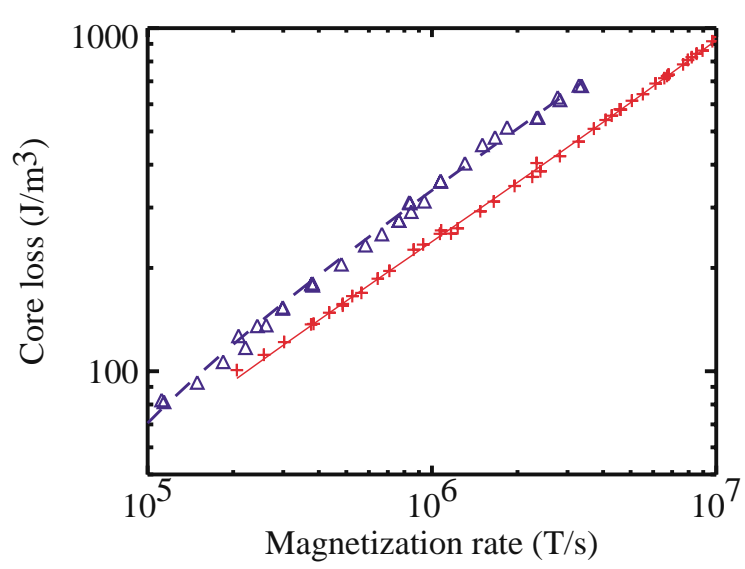

FIG. 11. (Color) Core loss versus magnetization rate for two METGLAS $2605 \mathrm{SC}$ cores at $1.6 \mathrm{~T}$ flux swing: $(\triangle$, blue, dashed line) annealed and rewound core Recirc- 7 and ( + , red, solid line) Mica-C14.

was worse than if we had used as-cast material without annealing. For short-pulse operation, we found that the maximum usable flux swing was $1.6 \mathrm{~T}$. In Fig. 11, we show the losses for the 2605 SC core that was rewound after annealing, and for comparison, the loss from the mica insulated core-14, also at the same $1.6 \mathrm{~T}$ flux swing. The losses are lower than in Figs. 6-8 only because the flux swing is less by factors of $27 \%-33 \%$. However, the losses are higher by $20 \%-50 \%$ than for a core of the same alloy, and at the same $1.6 \mathrm{~T}$ flux swing, that is annealed after winding rather than before. METGLAS 2605 SC and 2605 SA1 alloys embrittle during the anneal and become more difficult to wind. It became clear that anneal after winding offered significant advantages in performance, and probably in ease of fabrication, over using the as-cast alloy or the wind-after-annealing process; consequently we have concentrated our efforts on the anneal-after-winding approach. Coated cores offering higher packing fraction, which reduces the mass of cores, can be compatible with annealing after winding and can more easily be edge cooled by convection or conduction than with interleaved tape insulation that is wider than the alloy tape; consequently we have concentrated our efforts on coated cores.

2605 SA1 is a variant of 2605 SC, which has been optimized for low cost in manufacturing the alloy and in forming it into cores or transformers. It is specifically designed for the $60 \mathrm{~Hz}$ transformer market; nevertheless, its pulsed power performance approaches that of 2605 SC. We have tested it with three different coatings, which yield distinctly different results. The first coating tested was magnesium methylate on cores from National Arnold Magnetics (NAM) [16]. It produced the highest usable flux swings that we have obtained with amorphous metals, up to $2.7 \mathrm{~T}$. Losses versus magnetization rate are shown in Fig. 12 for flux swings of 2.2, 2.5, and $2.7 \mathrm{~T}$. These data do not extend to higher magnetization rates, because the larger mass of this core, $10.6 \mathrm{~kg}$, with an effective area of

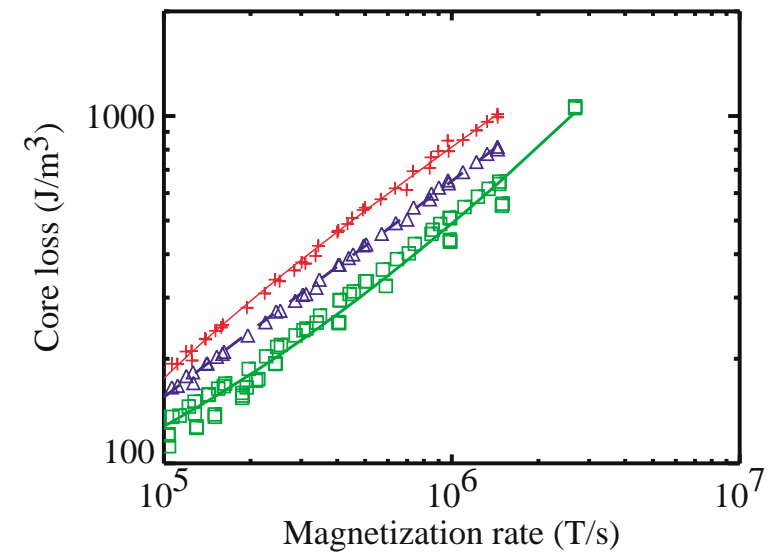

FIG. 12. (Color) Core loss versus magnetization rate for a METGLAS 2605 SA1 core, manufactured by NAM, insulated with a magnesium methylate coating and annealed. The data are for the listed flux swings: (+, red, solid line) at $2.70 \mathrm{~T} ;(\triangle$, blue, dashed line) at $2.50 \mathrm{~T}$; and ( $\square$, green, heavy line) at $2.20 \mathrm{~T}$.

$0.0025 \mathrm{~m}^{2}$, limited the magnetization rate that we could achieve with a $10 \mathrm{kV}$ pulser. These high flux swings imply that the remanent field was relatively high, probably near 0.89 of the saturation field of $1.59 \mathrm{~T}$ (manufacturer's dc rating), but we did not measure it with this core. At low magnetization rates, the losses are comparable to those shown for 2605 SC, but the losses increase more rapidly at higher magnetization rates. Out of several cores ordered with different thicknesses of this coating, only this one core with a thin coating performed well yielding a large flux swing with relatively low loss. Results with magnesium methylate and a variety of other coatings have been reported by others [10].

We subsequently had cores manufactured by MRTI, with 2605 SA1 as well as the 2605 SC materials discussed above. These produced lower flux swings, because the ratio of the remanent to saturation field was lower, in the range of 0.4-0.6; see Table II. The losses for three different cores are shown in Fig. 13. The core (SA1-01) designated by + (red) symbols appears to be especially attractive for low magnetization rates (although less attractive for high magnetization rates) where its losses are up to a factor of 2 below the other cores, despite its having the largest flux swing of $2.2 \mathrm{~T}$. This could be useful, but only if the variation in processing of core SA1-01 can be discovered and reproduced. (The variation is subtle, because this core was annealed along with core SA1-02 that does not show similar behavior [28].)

The other two cores appear to behave similarly, but this is misleading. Core SA1-04, designated by square (green) data points and a fitted solid (green) line, was potted in a silicone rubber-type material and achieved a flux swing of only $1.75 \mathrm{~T}$. This compares with $2.1 \mathrm{~T}$ for core SA1-02 which is designated by triangle (blue) data points and a dashed fitted line. Potting can make cores easier to handle without risk of the laminations spilling off the core, 


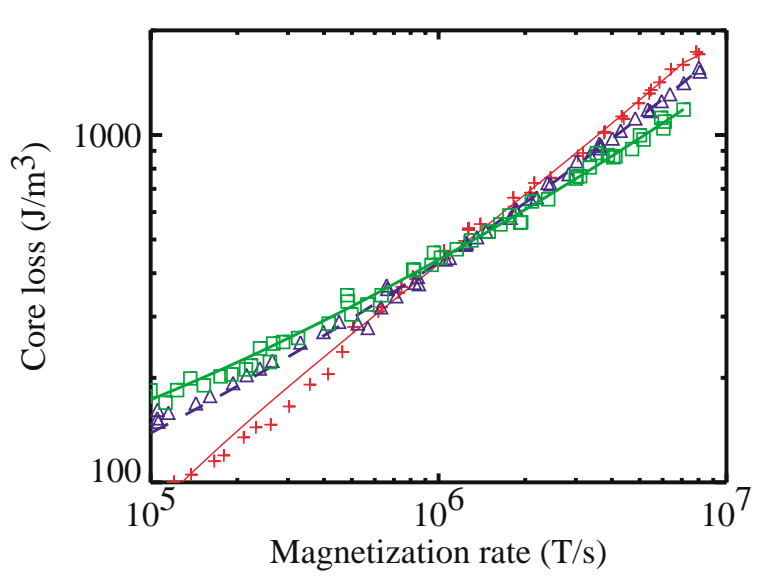

FIG. 13. (Color) Core loss versus magnetization rate for three METGLAS 2605 SA1 cores, The data are for the listed flux swings: ( $\square$, green, heavy line) MRTI SA1-04 at $1.75 \mathrm{~T}$; $(\triangle$, blue, dashed line) MRTI SA1-02 at 2.10 T; and $(+$, red, solid line) MRTI SA1-01 at 2.20 T.

especially for tapes that are narrower than the buildup. However, it is well known that any restraining of magnetostrictive alloys (e.g., 2605 SC and SA1), such as by coating or potting, can place the alloy in tension or compression. This tends to affect the flux swing (in this case reducing it by 17\%), and/or increase the losses [29,30].

For convenience in comparing the two METGLAS alloys with similar processing, in Fig. 14 we show two MRTI cores, SC-01 and SA1-02, along with a third core, that we will discuss below. The SC core losses are lower by up to $25 \%$ at high magnetization rates. This could be a result of the different formulation of the alloys; however, the 2605 $\mathrm{SC}$ is produced in thicknesses as low as $15 \mu \mathrm{m}$, whereas SA1 is made thicker for its intended $60 \mathrm{~Hz}$ market and has a typical thickness of about $23 \mu \mathrm{m}$. Since core losses have been shown to scale proportionally to the thickness, $d^{1}$ to

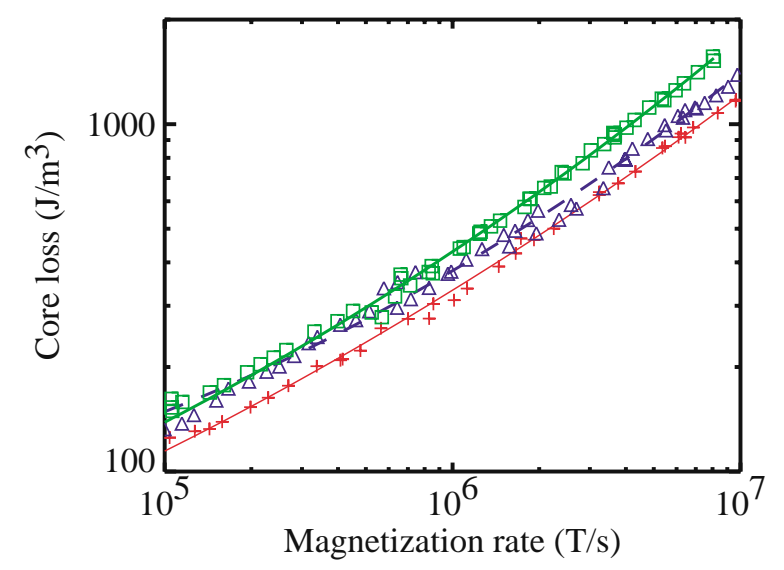

FIG. 14. (Color) Core loss versus magnetization rate for three METGLAS alloys. The data are for the listed flux swings: ( $\square$, green, heavy line) MRTI SA1-2 at 2.10 T; $(\triangle$, blue, dashed line) MRTI $2605 \mathrm{SC}-01$ at $2.20 \mathrm{~T}$; and $(+$, red, solid line) MRTI Thin-SA1-2 at $2.10 \mathrm{~T}$. $d^{2}$ [12], we investigated whether SA1 could be made as a thinner tape and whether it would then have lower losses. We placed a special order with Allied Signal (now Honeywell) to produce $50 \mathrm{~kg}$ of $5 \mathrm{~cm}$ wide SA1 with a thickness similar to that of 2605 SC. They achieved a thickness of $\sim 18$ to $21 \mu \mathrm{m}$ (measured by different methods). This material was then sent to MRTI and National Arnold Magnetics to be made into cores of $1-2 \mathrm{~kg}$ each. Three thin SA1 cores from MRTI are shown in Fig. 15. Comparing the best sample (the improvement with the other two thin SA1 samples is slightly to significantly less, Fig. 15) with the thicker SA1 in Fig. 14, we find that the losses are reduced nearly linearly with the tape thickness except at the highest magnetization rates where the reduction is somewhat greater. The thin SA1 losses are slightly less than the $2605 \mathrm{SC}$ core at all magnetization rates, because the flux swings differed slightly (2.1 T for thin SA1 and $2.2 \mathrm{~T}$ for the $2605 \mathrm{SC}$ core). At the same flux swing, the losses would be identical within the reproducibility of the cores.

A different coating process, trade named NAMLITE, is used by National Arnold Magnetics, Inc. [19]. As can be seen from Table II, the cores that we tested with this coating have a higher ratio of remanent to saturation field than the MRTI cores that we tested, which results in a larger flux swing. In Fig. 16, a NAMLITE coated core, NAM-SA1-th2, of thin 2605 SA1 is plotted for flux swings of $2.1,2.4$, and $2.65 \mathrm{~T}$, and is compared with an MRTI core, MRTI-SA1-Th2 for a flux swing of $2.1 \mathrm{~T}$. The losses for the $2.1 \mathrm{~T}$ flux swing overlay up to a magnetization rate of $8 \times 10^{5} \mathrm{~T} / \mathrm{s}$, then these NAMLITE core losses increase rapidly, apparently due to interlaminar current flow. No indication of such increased losses has been observed at SLAC with $2 \mu$ s duration pulses on a larger number of NAMLITE insulated cores [31]. These drive a voltage adder for klystron pulsers that is being developed for the next linear collider.

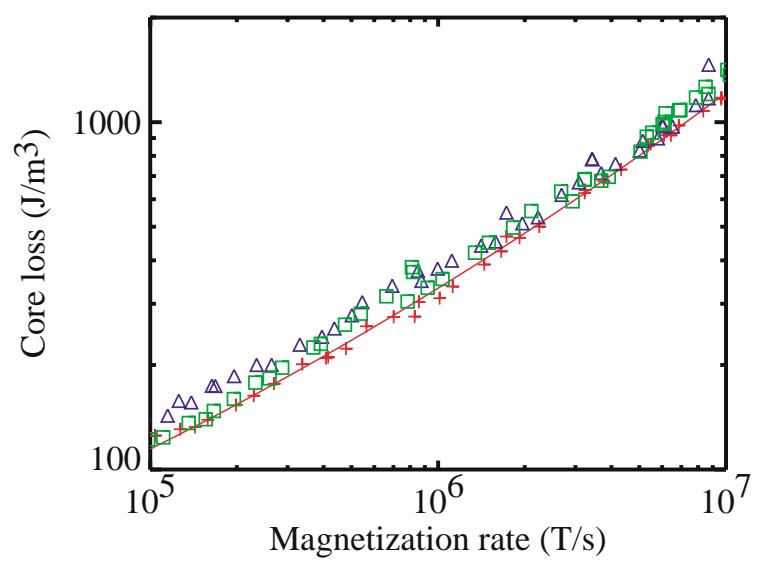

FIG. 15. (Color) Core loss versus magnetization rate for three METGLAS thin-SA1 cores, manufactured by MRTI. The data are for the listed flux swings: ( $\square$, green) MRTI Thin-2605 SA1-4 at 2.10 T; $(\triangle$, blue) MRTI Thin SA1-3 at 2.10 T; and $(+$, red, solid line) MRTI Thin SA1-2 at 2.10 T. 


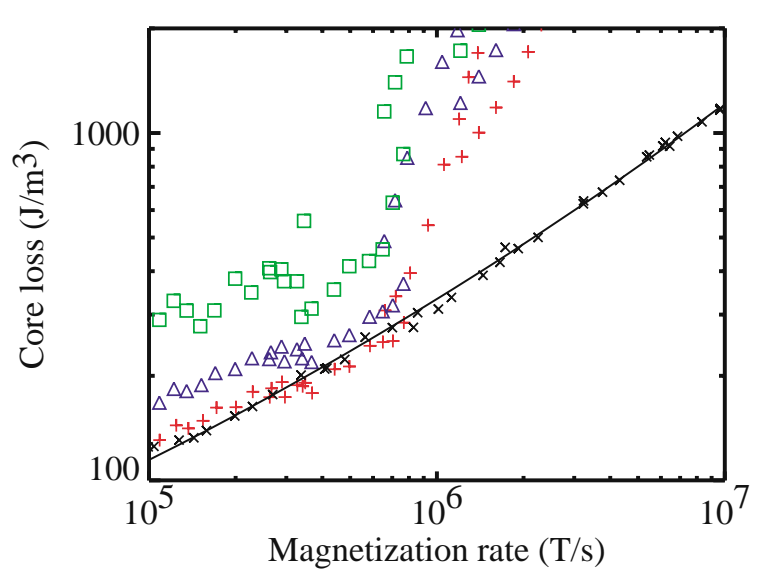

FIG. 16. (Color) Core loss versus magnetization rate for two METGLAS thin-SA1 cores, manufactured by NAM and MRTI. The data are for the listed flux swings: ( $\square$, green) NAM ThinSA1-2 at 2.65 T; $(\triangle$, blue) NAM Thin-SA1-2 at $2.40 \mathrm{~T} ;(+$, red $)$ NAM Thin-SA1-2 at $2.10 \mathrm{~T}$; and $(\times$, black, solid line) MRTI Thin SA1-2 at $2.10 \mathrm{~T}$.

\section{Nanocrystalline alloys}

Nanocrystalline materials have been intriguing for their low losses and the possibility of low-cost production, because the casting process is similar to that for amorphous metals [21]. As seen from Fig. 6, these cores of Hitachi Metals, Ltd., FINEMET FT-1H, deliver exceptionally low loss rates, especially at the lower magnetization rates. In Fig. 17, we observe that it is very reproducible from core to core. The usable flux swing varies over a $5 \%$ envelope

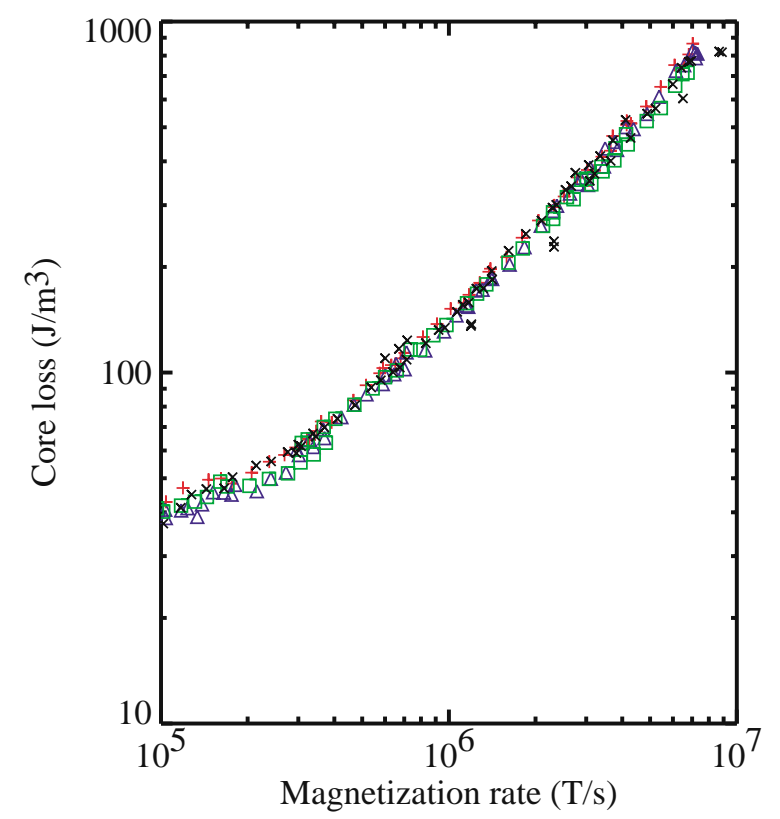

FIG. 17. (Color) Core loss versus magnetization rate for four FINEMET FT-1H nanocrystalline cores, manufactured by $\mathrm{Hi}-$ tachi. The data are for the listed flux swings: ( $\square$, green) 982-4 at $2.00 \mathrm{~T}$; $(\triangle$, blue) $982-3$ at $2.05 \mathrm{~T} ;(+$, red $) 982-2$ at $2.05 \mathrm{~T}$; and $(\times$, black) $982-1$ at $2.10 \mathrm{~T}$. from 2.0 to $2.1 \mathrm{~T}$, and the losses fall within an envelope whose width varies between $\sim 10 \%$ and $20 \%$ for the four cores shown. In Fig. 18, we investigate the results of operating the lowest flux swing core 982-4 at 2.1 T rather than the $2.0 \mathrm{~T}$ that it could deliver reliably. We found that the losses were generally higher than with core 982-1 which operates reliably at $2.1 \mathrm{~T}$, and that we had to discard a number of pulses where the flux swing of 982-4 fell below $2.1 \mathrm{~T}$. Even so, the losses were generally within $\sim 12 \%$, rising to $\sim 50 \%$ for a few pulses.

The higher flux swing alloy, FINEMET FT-2H, is also very consistent from core to core. The results from the four cores shown in Fig. 19 deliver flux swings within a $7 \%$ envelope and losses that are always within $\sim 20 \%$ and frequently within 5\%. This consistency indicates that the two lower curves in the summary plot, Fig. 6, are an accurate representation of results that can be expected with FINEMET.

We also obtained nanocrystalline cores from National Arnold Magnetics, made from the VACUUMSCHMELZE GMBH nanocrystalline alloy VITROPERM, with a magnesium methylate coating. The results are shown in Fig. 20. At low magnetization rates, these were less consistent than the FINEMET cores; on the other hand, they provided 5\%-10\% more flux swing than the FT-1H material (probably because the ratio of the remanent to saturation field was slightly higher; see Table III), and the losses were as low, or lower. At high magnetization rates, the National Arnold Magnetics core losses approached those of the FINEMET cores.

We compare a National Arnold Magnetics nanocrystalline core with the two FINEMET alloys in Fig. 21. Three of the curves are at $2.1 \mathrm{~T}$ flux swing, and the highest curve for FT-2H is at $2.4 \mathrm{~T}$. We can draw several conclusions from the data for these cores: (1) The National Arnold VITROPERM core losses are below the FT-1H

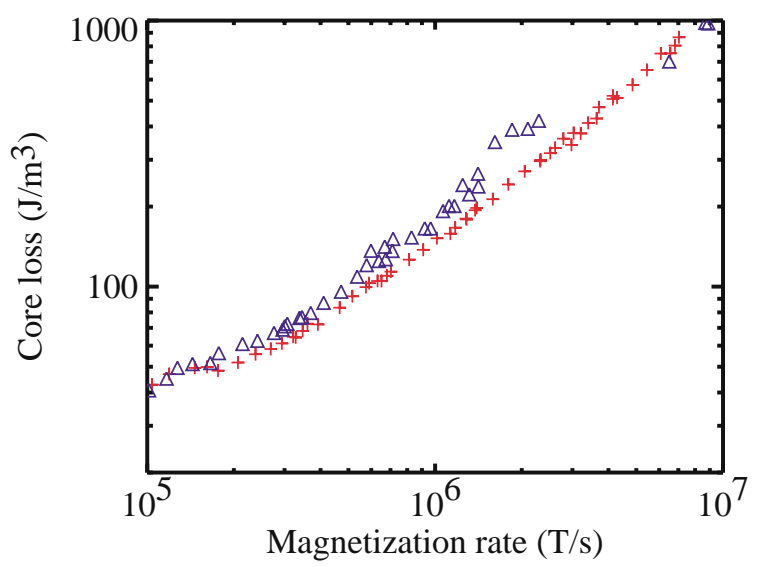

FIG. 18. (Color) Core loss versus magnetization rate for two FINEMET FT-1H nanocrystalline cores, manufactured by $\mathrm{Hi}$ tachi. The data are for the listed flux swings: $(\triangle$, blue) $982-4$ at $2.10 \mathrm{~T}$ and $(+$, red) $982-1$ at $2.10 \mathrm{~T}$. Not all pulses with core 982-4 reached $2.10 \mathrm{~T}$; these were removed from the data plotted. 


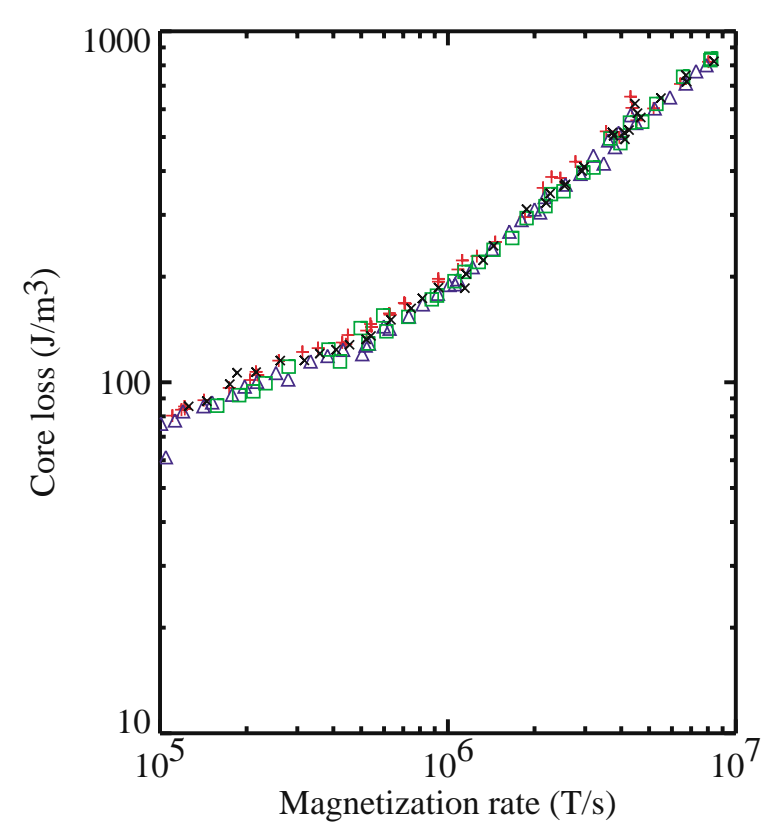

FIG. 19. (Color) Core loss versus magnetization rate for four FINEMET FT-2H higher flux-swing nanocrystalline cores, manufactured by Hitachi. The data are for the listed flux swings: ( $\square$, green) $99 \mathrm{Z}-3$ at $2.25 \mathrm{~T}$; $(\triangle$, blue) $99 \mathrm{Z}-2$ at $2.25 \mathrm{~T}$; $(+$, red) $99 \mathrm{Z}-1$ at $2.25 \mathrm{~T}$; and $(\times$, black) $99 \mathrm{Z}-4$ at $2.40 \mathrm{~T}$.

at all magnetization rates and similar to the FT-2H at $2.1 \mathrm{~T}$ flux swing at the highest magnetization rates. (2) As pointed out for Fig. 6, with high magnetization rates, FT-2H losses at $2.4 \mathrm{~T}$ flux swing are similar to FT-1H

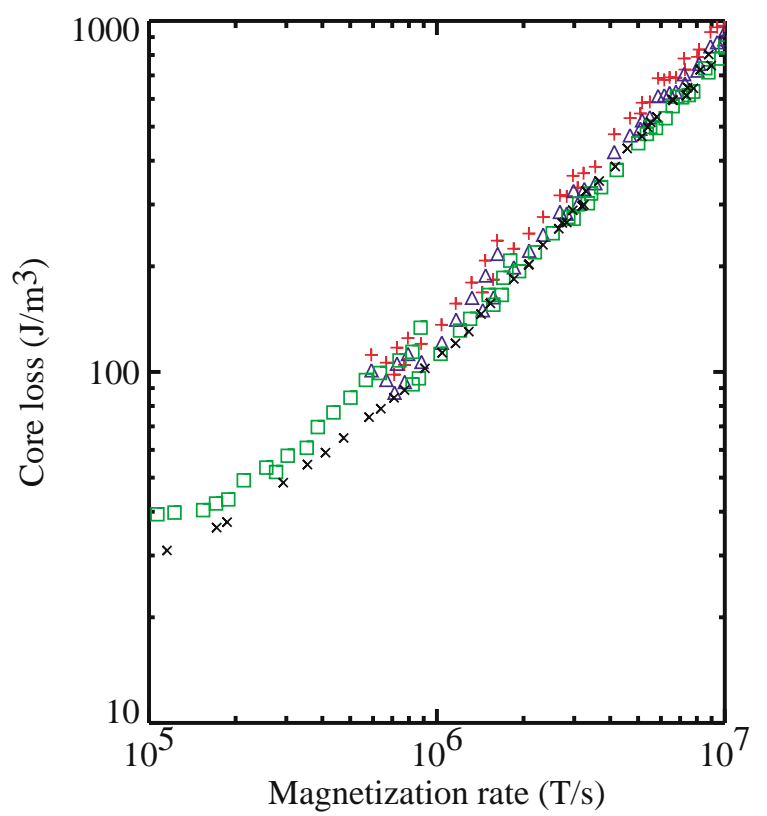

FIG. 20. (Color) Core loss versus magnetization rate for three Vitroperm nanocrystalline cores, manufactured by NAM, core-1 listed at two flux swings. The data are for the listed flux swings: ( $\square$, green) NAM-nano-2 at $2.15 \mathrm{~T}$; $(\triangle$, blue) NAM-nano-1 at $2.15 \mathrm{~T}$; $(+$, red) NAM-nano-1 at $2.25 \mathrm{~T}$; and $(\times$, black) NAMnano-3 at $2.10 \mathrm{~T}$.

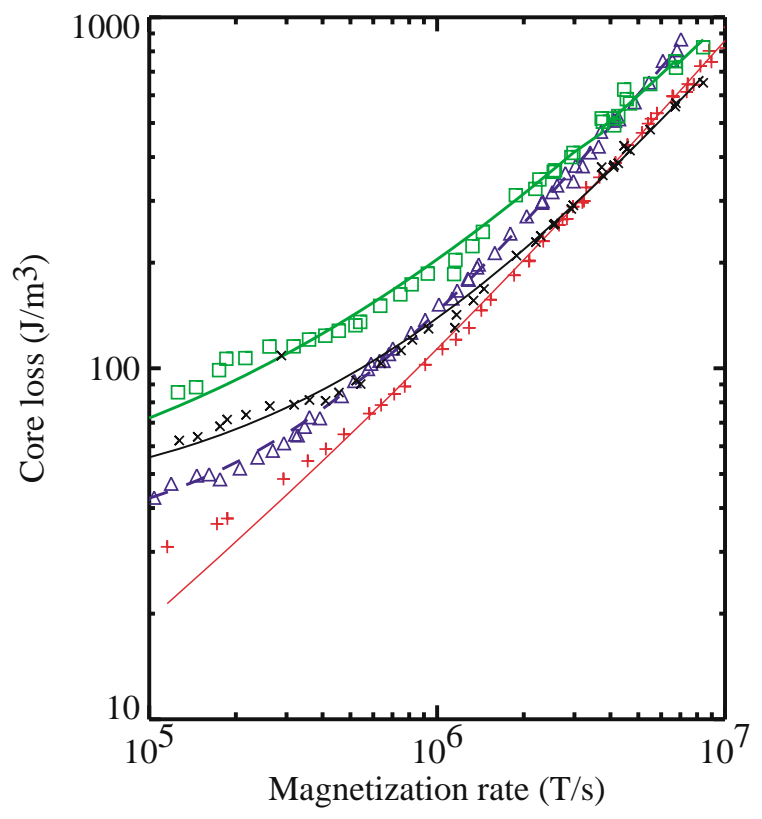

FIG. 21. (Color) Core loss versus magnetization rate for three varieties of nanocrystalline cores, manufactured by Hitachi and NAM, one core shown twice. The data are for the listed flux swings: ( $\square$, green, heavy line) FT-2H 99Z-4 at $2.40 \mathrm{~T}$; $(\times$, black, solid line) FT-2H 99Z-4 at $2.10 \mathrm{~T}$; $(\triangle$, blue, dashed line) FT-1H 982-1 at 2.10 T; and (+, red, solid line) NAM-nano-3 at $2.10 \mathrm{~T}$.

losses at 2.1 T. (3) For two cores with the same volt seconds, the higher flux-swing material can use a smaller volume core; therefore the FT-2H losses would be less than FT-1H losses, at high magnetization rates, when normalized to core volt seconds rather than to core volume.

\section{Silicon steel}

We obtained 3\% grain-oriented silicon-steel cores from Magnetic Metals, processed for pulse applications, and uncased with a light epoxy dip [16]. We obtained three different thicknesses, three cores of $25 \mu \mathrm{m}$ thick tape, and one each of $50 \mu \mathrm{m}, 100 \mu \mathrm{m}$, and a selected higher-flux silicon steel also $100 \mu \mathrm{m}$ thick. The losses from the four types are shown in Fig. 22. They mostly follow the expected linear increase of losses with tape thickness at low magnetization rates, transitioning towards scaling with the square of the tape thickness at high magnetization rates, with the transition occurring at lower levels with thicker tapes [12]. The exception is that the losses for the 25 and $50 \mu \mathrm{m}$ thicknesses are nearly equal near $10^{5} \mathrm{~T} / \mathrm{s}$. If this were to prove reproducible, the $50 \mu \mathrm{m}$ tape thickness would be very desirable near $10^{5} \mathrm{~T} / \mathrm{s}$, for both its higher flux swing and its lower cost. The selected $100 \mu \mathrm{m}$ material had a slightly higher flux swing, although no higher than the $50 \mu \mathrm{m}$ unselected material, and also slightly lower losses than the unselected $100 \mu \mathrm{m}$ material. As can be seen from Table III, the squareness of the $B-H$ loop is quite high; 


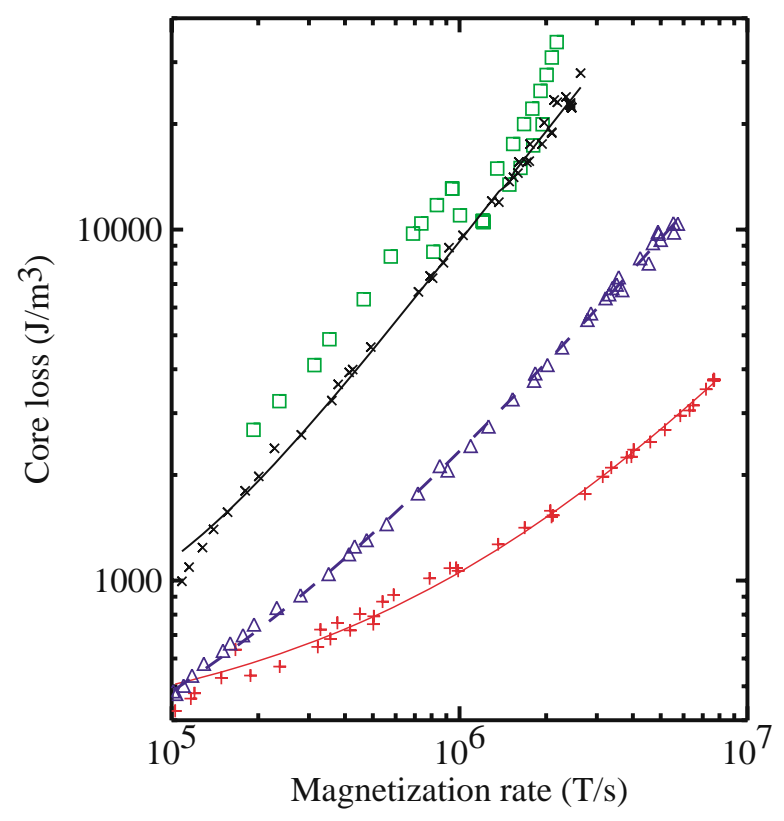

FIG. 22. (Color) Core loss versus magnetization rate for four $3 \%$ silicon steel cores, manufactured by Magnetic Metals. The data are for the listed flux swings and lamination thickness: ( $\square$, green) $100 \mu \mathrm{m}$ thick at $3.20 \mathrm{~T} ;(\times$, black, solid line) selected $100 \mu \mathrm{m}$ thick at $3.30 \mathrm{~T}$; $(\triangle$, blue, dashed line) $50 \mu \mathrm{m}$ thick at $3.30 \mathrm{~T}$; and $(+$, red, solid line) $25 \mu \mathrm{m}$ thick at $3.00 \mathrm{~T}$.

the ratio $B_{r} / B_{s}$ ranged from 0.75 for the $25 \mu \mathrm{m}$ material to 0.84 for the other thicknesses.

We compare the three $25 \mu \mathrm{m}$ cores in Fig. 23, finding very good consistency between core losses that ranged from a $\sim 2 \%$ to a $20 \%$ envelope over the range of magnetization rates studied.

We also obtained several 6\% silicon steel cores through Northstar Research Corp. [16]. The results from four

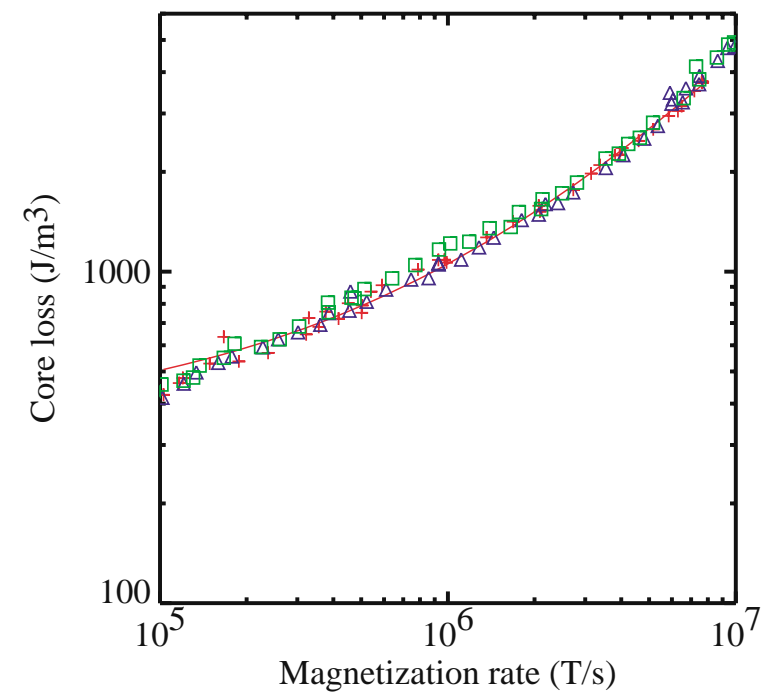

FIG. 23. (Color) Core loss versus magnetization rate for three $25 \mu \mathrm{m}$ thick $3 \%$ silicon steel cores, manufactured by Magnetic Metals. The data are all at a flux swing of $3.0 \mathrm{~T}$ : ( $\square$, green) 3301-3; ( $\triangle$, blue) 3301-2; and (+, red, solid line) 3301-1.

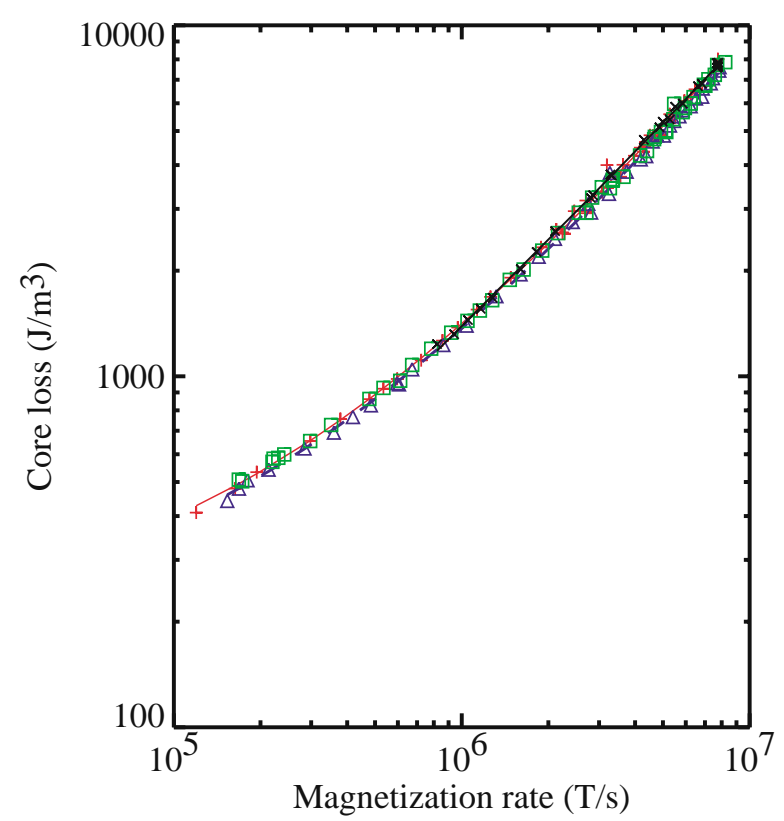

FIG. 24. (Color) Core loss versus magnetization rate for four $6 \%$ silicon steel cores. The data are all at a flux swing of $2.40 \mathrm{~T}$ : ( $\times$, black) Si6-4; ( $\square$, green) Si6-3; $(\triangle$, blue) Si6-2; and (+, red, solid line) Si6-1.

cores, at a flux swing of $2.4 \mathrm{~T}$, are shown in Fig. 24. This also shows very good consistency between cores, similar to that for the $3 \%$ silicon steel. One of the cores produced usable output to 2.6 T. In Fig. 25, the loss rate for this core is plotted for flux swings of $2.4,2.5$, and $2.6 \mathrm{~T}$, along with

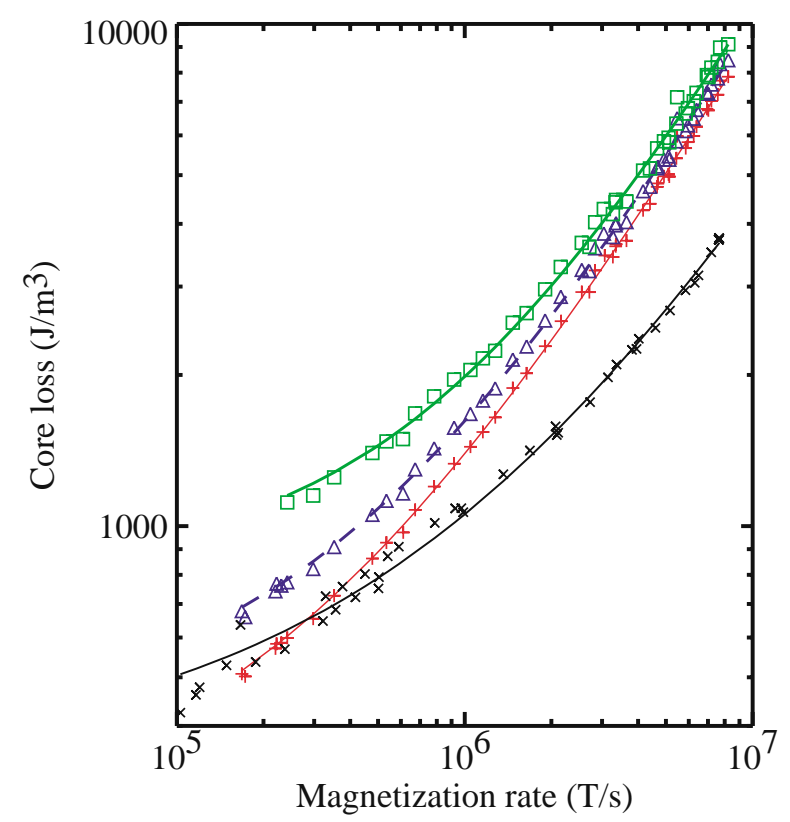

FIG. 25. (Color) Core loss versus magnetization rate comparing a $6 \%$ silicon steel core, at three flux swings, with a $25 \mu \mathrm{m}$ thick $3 \%$ silicon steel core. The data are for the listed flux swings: ( $\square$, green, heavy line) Si6-3 at $2.60 \mathrm{~T}$; $(\triangle$, blue, dashed line) Si6-3 at 2.50 T; (+, red, solid line) Si6-3 at 2.40 T; and $(\times$, black, solid line) $3301-1$ at $3.00 \mathrm{~T}$. 
a $25 \mu \mathrm{m}, 3 \%$ silicon steel core at a flux swing of $3.0 \mathrm{~T}$. The 3\% silicon steel is superior over the entire range of magnetization rates, offering a $25 \%$ higher flux swing for the same or lower losses.

Before choosing to use $3 \%$ silicon steel, one might also evaluate METGLAS $2605 \mathrm{CO}$, which was not considered in this study because of the higher cost of cobalt and its higher losses [12]. The $\sim 18 \%$ cobalt content would add $\$ 2.70 / \mathrm{kg}$ to the material costs, at the current costs of cobalt discussed at the end of Sec. II. The losses should be similar to those of $25 \mu \mathrm{m} \mathrm{3 \%}$ silicon steel, and with a saturation field of $1.8 \mathrm{~T}$, the usable flux swing could reach $3.3 \mathrm{~T}$ [14]. In other references, this material was found to be much less sensitive to coating thickness and also tolerated rewinding after annealing with less degradation, compared with 2605 SC $[9,10]$.

In most cases, cores of one alloy and type of coating show good reproducibility of the primary performance parameters from core to core. The parameters include the flux swing, the ratio of the remanent to saturation field, and the losses. An apparent exception in Table III, 3\% silicon steel, also shows good reproducibility when one considers one thickness of alloy tape at a time. For this, it is necessary to understand the nomenclature used for silicon steel under "Coating label." The first two digits (e.g., 33) refer to the alloy, the next two (e.g., 01) to the thickness in mils $(1 \mathrm{mil}=25.4 \mu \mathrm{m})$, and the final digit (e.g., -1$)$ to the core number. Then we find that the losses scale linearly to quadratically with the tape thickness, as has been found previously [12].

\section{COATINGS}

At their best, cores that are annealed after winding exhibit high consistency in the performance factors from core to core and yield performance near the maximum possible. As discussed, interlaminar insulation is required for pulsed operation. The characteristics that make an insulating coating (or cowound tape) suitable for anneal after wind are the following.

(i) Hold voltage of $0.1-100 \mathrm{~V}$ per layer. At the low energy end of a driver accelerator, pulses are longer (up to 10 's of $\mu \mathrm{s}$ ) so the voltage is lower for similar voltsecond cores. At the high energy end of a driver, pulses are expected to be in the range of 100-300 ns, and the voltage is correspondingly higher. Occasional shorts can be permitted with little effect on performance, but the performance degrades if multiple shorts are aligned to provide low-inductance eddy-current paths. By means of Faraday's law, Eq. (1), we evaluate the maximum interlaminar voltage achieved in our tests for each type of core, Table V. If breakdown occurred, the voltage is listed in boldface. The tape thickness was measured by either a micrometer or from weighing a measured length of tape. In some cases, we got a different thickness by each method. In these cases, thin SA1 and FT-1H and FT-2H, we arbitrar-
TABLE V. Maximum interlaminar voltage applied without breakdown, or (boldface) at breakdown. The tape thickness is $\delta$. The peak value of $d B / d t$ and the interlaminar voltage is listed.

\begin{tabular}{lcccr}
\hline \hline \multicolumn{1}{c}{ Alloy/Insulation } & $\begin{array}{c}\text { Width } \\
(\mathrm{m})\end{array}$ & $\begin{array}{c}\delta \\
(\mu \mathrm{m})\end{array}$ & $\begin{array}{c}d B / d t \\
(\mathrm{~T} / \mu \mathrm{s})\end{array}$ & $\begin{array}{c}\text { Volts } \\
(\mathrm{V})\end{array}$ \\
\hline SC-14/Mica & 0.051 & 15 & 10.0 & 7.6 \\
SC-02/NaSi & 0.022 & 15 & 10.0 & 3.3 \\
$\mathrm{SA} 1 / \mathrm{Meth}$ & 0.051 & 23 & 2.8 & 3.3 \\
$\mathrm{SA1}$-A/NAM & 0.051 & 23 & 1.5 & $\mathbf{1 . 8}$ \\
$\mathrm{SA} 1-02 / \mathrm{NaSi}$ & 0.025 & 23 & 8.0 & 4.7 \\
ThSA1-3/NAMLITE & 0.051 & 21 & 1.6 & $\mathbf{1 . 7}$ \\
ThSA1-6/NAMLITE & 0.051 & 18 & 0.5 & $\mathbf{0 . 5}$ \\
ThSa1-4/NaSi & 0.051 & 18 & 10.0 & 9.2 \\
FT1H-1/SiO 2 & 0.025 & 19 & 9.0 & 4.3 \\
FT2H-4/SiO & 0.025 & 16 & 8.0 & 3.2 \\
Nano1/MgMethylate & 0.025 & 20 & 10.0 & 5.0 \\
3\% SiFe1/pulse grade & 0.038 & 25 & 8.0 & 7.6 \\
3\% SiFe2/pulse grade & 0.038 & 50 & 5.8 & 11.0 \\
3\% SiFe4/pulse grade & 0.038 & 100 & 2.7 & 10.0 \\
6\% SiFe/(?) & 0.025 & 25 & 8.0 & 5.0 \\
\hline \hline
\end{tabular}

ily assigned each value to a different line; the achieved interlaminar voltage is uncertain by that amount. A larger uncertainty arises if the core had a large ratio of inner to outer diameter, for which it has been shown that the radial voltage gradient initially peaks across the inner laminations until they saturate, then the peak voltage propagates outwards [32]. The peak interlaminar voltage may then be 2-3 times the average that we show in Table V. At higher magnetization rates near $10^{7} \mathrm{~T} / \mathrm{s}$, the alloy tape width will be restricted to much less than the maximum $0.15-0.20 \mathrm{~m}$. Narrower tape not only reduces the interlaminar voltage, but it also reduces the radial electric field along the edge of the core to below the breakdown limit in its environment.

(ii) Withstand annealing temperatures in the range of $325-400{ }^{\circ} \mathrm{C}\left(550-650{ }^{\circ} \mathrm{C}\right.$ for nanocrystalline) for about $2 \mathrm{~h}$ and retain, or regain, the other desired properties after cooldown. The coating should be "well cured" after annealing, if not before. Coatings that are cured and work well for a nanocrystalline core after annealing above $550{ }^{\circ} \mathrm{C}$ may not be cured for an amorphous core after annealing below $400{ }^{\circ} \mathrm{C}$.

(iii) Apply minimal mechanical stress to the alloy. Matching the coefficients of thermal expansion would be ideal. Alternatively, the insulation can be made so thin (or of low tensile strength) that it cannot apply stress, as long as it still holds sufficient voltage after winding and annealing. High mechanical stress degrades the ratio $B_{r} / B_{s}$ resulting in a lower flux swing, in some cases indistinguishable from unannealed cores [15].

(iv) Thin, $<2-3 \mu \mathrm{m}$, to maintain the PF near or above $80 \%$. This criterion is frequently less stringent than the minimal stress requirement.

(v) Coating the alloy is preferable to a cowound tape insulator to enable simpler winding, thinner insulation, and 
higher $\mathrm{PF}$, and the elimination of insulation overhang at the sides of the core, which impedes cooling and hinders annealing a core on its side. On the other hand, cowound ribbon insulation should allow higher interlaminar voltage.

(vi) Potential of low cost restricts the cost of the insulator material, the cost of applying it, and of drying, curing, and winding it. Some materials, such as polyimide and Parylene-N are apparently costly at nearly $\$ 1000 / \mathrm{kg}$, but could be acceptable if applied in thin enough coatings $(5-25 \mathrm{~nm})$. These plastics can withstand slightly over $400{ }^{\circ} \mathrm{C}$, so they might withstand the annealing of amorphous cores, but not of nanocrystalline cores. Vacuum vapor deposition (e.g., Parylene-N) will be more costly than dipping the metal tape in a dilute coating solution (e.g., polyimide, sodium silicate). Finally, we prefer a rapid cure at near room temperature, sufficient for the insulation to survive the stress and abrasion during winding.

(vii) Lifetime of $0.5-1 \times 10^{10}$ pulses (the lifetime of a power plant should be $30 \mathrm{yr}$ or more at $5-10 \mathrm{~Hz}$ ) avoids the need for replacing components during the life of a driver. Core lifetime needs to be addressed as it has not yet been tested to within even a few orders of magnitude of the requirement. We have not performed lifetime tests on any of the cores discussed in this paper. Lifetime also involves surviving ambient conditions before and after installation. For example, magnesium methylate is hygroscopic [10], so it will have a long lifetime only if low humidity is maintained. Long life is also aided by a coating that provides protection against rusting or other corrosion, and that is not easily punctured by small bumps or asperities on the ribbon surface [10].

(viii) At the end of life, the metal and insulator should be easily separated, to allow recycling of both materials.

The quality of coatings has been ranked in three ways in this paper: (a) Does the interlaminar breakdown voltage, and the resulting rapid increase in loss rate, limit the core width or the magnetization rates to $<10^{7} \mathrm{~T} / \mathrm{s}$ ? (b) How high a ratio of remanent to saturation magnetic field is obtained? (c) How consistent and reproducible is the performance? The coatings used on nanocrystalline and on silicon steel cores did well on all criteria. The situation was not as good with amorphous alloys, where the coatings met only one of criteria (a) and (b). For example, the samples we tested with a NAMLITE coating excel in criterion (b) with a high remanent field, yielding a high usable flux swing; however the coating apparently breaks down for interlaminar voltages exceeding $0.5-2 \mathrm{~V}$, Table V. Other coatings such as sodium silicate, magnesium methylate, and $\mathrm{SiO}_{2}$ show no signs of breakdown at interlaminar voltages up to 8-10 V; however for the sodium-silicate coated cores, the ratio of remanent to saturation field is lower, leading to lower usable flux swings. These two issues are related-thicker coatings hold voltage better, but are also capable of applying more mechanical stress to the alloy during cooldown from the magnetic anneal. These coatings tend to have lower packing fractions, consistent with being thicker. From these results it is clear that there is room for improvement in coating technologies, and perhaps in annealing processes, in order to simultaneously approach the maximum performance in flux swing and packing fraction with adequate voltage holding. The coating/annealing processing is mostly very successful in meeting one requirement: consistent performance from core to core.

\section{CONCLUSIONS}

We have discussed three classes of magnetic alloys and several coatings to provide interlaminar insulation.

The highest loss material, that could be usable for HIF power plants, is $3 \%$ silicon steel in either $50 \mu \mathrm{m}$ thickness, which yielded a $3.3 \mathrm{~T}$ flux swing, or $25 \mu \mathrm{m}$ thickness, which yielded a $3.0 \mathrm{~T}$ flux swing. We also evaluated $3 \%$ silicon steel with a thickness of $100 \mu \mathrm{m}$, for which we judged the losses unacceptable. These flux swings are higher than with the amorphous materials, which allows reducing the size of the cores. If the $3 \%$ silicon steel is restricted to longer pulse duration applications near the injector, the total increase in time-averaged pulser power to drive the cores can be well under $1 \mathrm{MW}$, out of a few tens of megawatts average-pulser power in a power plant.

Amorphous materials, represented by METGLAS 2605 SA1 and 2605 SC form the middle group. We achieved flux swings of 2.7 and $2.25 \mathrm{~T}$, respectively. These flux swings are sufficiently large, the losses are sufficiently low, and the production costs are anticipated to be low, so these materials appear to be attractive for the bulk of an HIF driver. Accounting for only core losses, the acceleration efficiency slightly exceeds $50 \%$ for pulses shorter than $1 \mu \mathrm{s}$, in a $3.3 \mathrm{MJ}, 1.3 \mathrm{GeV} \mathrm{Kr}{ }^{+}$driver [7]. The difference in the flux swings between 2605 SA1 and 2605 SC is attributed to differences in the coatings and processing that affect the remanent magnetic field, rather than differences in the magnetic alloys, which should perform more similarly.

Nanocrystalline materials, represented by FINEMET FT-2H and FT-1H, form the lowest loss group. The flux swings are $2.25-2.4$ and $2.0-2.1 \mathrm{~T}$, respectively. This material would be most useful for applications where the pulser costs exceed the core costs. An example of this is a high-precision feedback-controlled correction pulser [8]. Another example is studying the effects (on pulser operation and beam dynamics) of a higher ratio of the beam current to the core magnetization current in near-term experiments with from one to a few beams that have much lower total-beam current than fusion drivers with the order of 100 parallel beams.

At their best, cores that are annealed after winding exhibit high consistency in the performance factors from core to core and yield performance near the maximum possible. As discussed, interlaminar insulation is required for pulsed 
operation. We prefer insulating coatings to interleaved ribbon insulation in order to achieve easier winding, thinner insulation for higher packing fraction, and greater ease of cooling the alloy ribbon.

The quality of coatings has been ranked in three ways in this paper: (a) Does the interlaminar breakdown voltage, and the resulting rapid increase in loss rate, limit the core width or the magnetization rates to $<10^{7} \mathrm{~T} / \mathrm{s}$ ? (b) How high a ratio of remanent to saturation magnetic field is obtained? (c) How consistent and reproducible is the performance? The coatings used on nanocrystalline and on silicon steel cores did well on all criteria. The situation was not as good with amorphous alloys, where the coatings met only one of criteria (a) and (b); either the coatings broke down and did not prevent interlaminar current flow or they reduced the remanent field and therefore the flux swing. These two issues are related-thicker coatings hold voltage better, but are also capable of applying more mechanical stress to the alloy during cooldown from the magnetic anneal. From these results it is clear that there is room for improvement in coating technologies, and perhaps in annealing processes, in order to simultaneously approach the maximum performance in flux swing and packing fraction with adequate voltage holding. The coating/annealing processing is mostly very successful in meeting one requirement - consistent performance from core to core.

\section{ACKNOWLEDGMENTS}

We are grateful to Roger Bangerter and Grant Logan for support and critiques of this work, to Carl H. Smith for suggestions throughout this work, and to Gennnady Mamaev, Lou Reginato, Will L. Waldron, and Richard Wood for many discussions. Mark Fowler, Ralph Hipple, William Strelo, and their associates provided excellent technical support. This work was performed by the University of California Lawrence Livermore National Laboratory under the auspices of the U.S. Department of Energy under Contract No. W-7405-ENG-48 and Lawrence Berkeley National Laboratory DE-AC03-76F00098.

[1] R. O. Bangerter, Nuovo Cimento Soc. Ital. Fis. 106A, 1445 (1993).

[2] W. R. Meier, J. J. Barnard, and R. O. Bangerter, Nucl. Instrum. Methods Phys. Res., Sect. A 464, 433 (2001).

[3] R. W. Moir et al., Fusion Technol. 25, 5 (1994).

[4] R. W. Moir, Nucl. Instrum. Methods Phys. Res., Sect. A 464, 140 (2001).

[5] C. Bauman, S. Pemberton, and P. F. Peterson, Nucl. Instrum. Methods Phys. Res., Sect. A 464, 400 (2001).

[6] P. Seidl, R. Bangerter, C. Celata, A. Faltens, V. Karpenko, E. Lee, S. Lund, A. Molvik, and I. Haber, in Proceedings of the 2001 Particle Accelerator Conference, Chicago, IL (IEEE, Piscataway, NJ, 2001), p. 2932.
[7] A. W. Molvik and A. Faltens, Nucl. Instrum. Methods Phys. Res., Sect. A 464, 445 (2001).

[8] A. Faltens, V. Brady, D. Brodzik, L. Hansen, L. J. Laslett, S. Mukherjee, D. Bubp, D. Ravenscroft, and L. Reginato, in Proceedings of the 1989 IEEE Particle Accelerator Conference, Chicago, IL (IEEE, Piscataway, NJ, 1989), p. 965.

[9] A. Faltens, S. S. Rosenblum, and C. H. Smith, J. Appl. Phys. 57, 3508 (1985).

[10] C. H. Smith, B. N. Turman, and H. C. Harjes, IEEE Trans. Electron Devices 38, 750 (1991).

[11] A. W. Molvik, W. R. Meier, A. Faltens, L. Reginato, and C. H. Smith, Proceedings of the Linac98 Conference, http://www.aps.anl.gov/conferences/LINAC98/

[12] C. H. Smith and D. M. Nathasingh, in Proceedings of the 16th Power Modulator Symposium (IEEE, New York, 1984), p. 240.

[13] V. R. V. Ramanan, C. H. Smith, and G. E. Fish, Key Engineer. Mater. 13, 849 (1987).

[14] C. H. Smith, J. Appl. Phys. 67, 750 (1990).

[15] A. W. Molvik, A. Faltens, L. Reginato, M. Blaszkiewicz, C. Smith, and R. Wood, Nucl. Instrum. Methods Phys. Res., Sect. A 415, 315 (1998).

[16] Reference herein to any specific commercial product, process, or service by trade name, trademark, manufacturer, or otherwise, does not necessarily constitute or imply its endorsement, recommendation, or favoring by the United States Government or the University of California.

[17] S. Nakajima, S. Arakawa, Y. Yamashita, and M. Shiho, Nucl. Instrum. Methods Phys. Res., Sect. A 331, 5556 (1993).

[18] G. Mamaev, I. Bolotin, A. Ctcherbakov, S. Mamaev, S. Poutchkov, and I. Tenyakov, in Proceedings of the 1997 Particle Accelerator Conference, Vancouver, Canada (IEEE, Piscataway, NJ, 1997), p. 1313.

[19] R.H. Wood and R. Lathlaen, in Proceedings of the 12th IEEE Pulsed Power Conference (IEEE, Piscataway, NJ, 1999), p. 1313.

[20] A. Faltens, M. Firth, D. Keefe, and S. S. Rosenblum, IEEE Trans. Nucl. Sci. 30, 3669 (1983).

[21] Y. Yoshizawa, S. Oguma, and K. Yamauchi, J. Appl. Phys. 64, 6044 (1988).

[22] Dow Jones Newswires (2001), available to subscribers to wsj.com

[23] R. Scanlon (private communication).

[24] C. H. Smith (private communication).

[25] A. W. Molvik, W. R. Meier, R. W. Moir, and A. Faltens, in Proceedings of the 1997 Particle Accelerator Conference, Vancouver, Canada (Ref. [18]), p. 1503.

[26] W. Waldron and L. Reginato, in Proceedings of the 24th IEEE Power Modulator Symposium (IEEE, Piscataway, NJ, 2000), p. 179.

[27] D. M. Nathasingh, C. H. Smith, and A. Datta, IEEE Trans. Magn. 20, 1332 (1984).

[28] G. Mamaev (private communication).

[29] R. M. Bozorth, Ferromagnetism (D. Van Nostrand Company, Inc., Princeton, NJ, 1951).

[30] V. R. V. Ramanan, C. H. Smith, and L. Barberi, J. Appl. Phys. 57, 3493 (1985).

[31] E. G. Cook (private communication).

[32] S. D. Winter, R. W. Kuenning, and G. G. Berg, IEEE Trans. Magn. 6, 41 (1970). 